\title{
Las dimensiones morales del desarrollo
}

David M. Smith

Queen Mary and Westfield College

University of London

Department of Geography

Mile end Road

London E1 4NS

U.K.

Tel. (98171) 9755400

Fax (98181) 9816276

\section{Resumen}

- Promover el desarrollo es un proyecto moral, relacionado con cierta concepción del bien humano. Sin embargo, pocas veces se indaga el contenido moral de los problemas del desarrollo. La primera parte de este artículo destaca algunas dimensiones morales de varios aspectos del desarrollo, incluyendo necesidades y derechos humanos, justicia distributiva y el variable papel del espacio geográfico. En la segunda parte se presentan dos estudios de caso donde se exploran las bases morales de estrategias nacionales específicas. El primer caso es el Reino Unido, para el que se analizan la Carta de los Ciudadanos y el reporte de la Comisión de Justicia Social, en un contexto de creciente desigualdad social. El segundo caso es Sudáfrica, con el análisis del Programa de Reconstrucción y Desarrollo introducido para combatir la pobreza y la desigualdad racial en los años posapartheid. Aunque estos contextos son diferentes,

- en ambos casos los propósitos morales se enfrentan con restricciones políticas y económicas, dando lugar a preguntas sobre la definición de calidad de vida. El artículo concluye con algunas reflexiones sobre la tensión entre particularidad y universalidad en los planteamientos sobre el desarrollo. 
Introducción

En su libro Empowerment: The Politics of Alternative Development, John Friedmann (1992) intenta proporcionar lo que describe como un marco moralmente informado. Desarrollo alternativo es "la continua lucha [...] por las exigencias morales de la clase pobre desprovista de poder frente a los poderes hegemónicos existentes" (Friedmann, 1992:8). Proponer una alternativa a la estrategia de crecimiento maximizado a largo plazo que domina la prevaleciente teoría del desarrollo "tiene más que ver con moralidad que con técnica" (Friedmann: 1992:10). Sus planteamientos fundamentales son que toda persona tiene derecho a adecuadas condiciones materiales de vida y a ser un sujeto políticamente activo en su propia comunidad, basándose en tres pilares: derechos humanos, derechos ciudadanos y florecimiento humano. Los primeros dos son ejes del discurso moral moderno, mientras que el tercero puede rastrearse desde los escritos clásicos sobre la calidad de vida.

Lo asombroso de este planteamiento no es tanto su contenido como su novedad. Si el desarrollo implica alguna idea de progreso o mejoramiento humano, entonces su promoción es un proyecto profundamente moral. Sin embargo, rara vez se explicita esta dimensión moral. Las teorías oficiales a las que Friedmann opone su alternativa quizás apareen crecimiento con igualdad, e incluso aseguren que uno lleva a la otra, pero en la práctica la equidad se queda en gestos vagos hacia la reducción de la desigualdad o desequilibrio social y regional. Es probable que cualquier estrategia de desarrollo esté regida por ciertas consideraciones de justicia social, en el sentido de búsqueda de alguna (re)distribución de los beneficios del crecimiento económico, pero pocas veces se aclara la justificación moral de los resultados de distribuciones particulares.

Todo esto refleja las limitadas conexiones entre, por un lado, la teoría y práctica de la planeación del desarrollo y, por el otro, la filosofía moral y política. Y los pocos vínculos que aparecen en la literatura en general provienen de filósofos que abordan de manera algo abstracta los grandes aspectos del desarrollo, como la justicia internacional (e.g. Attfield y Wilkins, 1992; Thompson, 1992), y no de planificadores en busca de bases morales para propuestas específicas. De ahí la fuerza del argumento de Corbridge (1993:467): "preguntarse por las fronteras entre la filosofía política y moral y los estudios sobre el desarrollo, plantea serios problemas para la praxis de este último".
El presente artículo llama la atención hacia algunas dimensiones morales del desarrollo. Comienza considerando desde una perspectiva moral varios de sus aspectos, incluyendo necesidades y derechos humanos, justicia distributiva y la importancia del espacio geográfico. Luego se exploran dos casos que recientemente han atraído bastante interés. El primero es el Reino Unido, para el cual se revisan la iniciativa de Carta de los Ciudadanos propuesta por el gobierno conservador y las propuestas de la Comisión de Justicia Social fomentadas por el Partido Laborista, ambas vistas a la luz de la creciente desigualdad en la sociedad británica. El segundo caso es Sudáfrica, con su Programa de Reconstrucción y Desarrollo introducido por el Congreso Nacional Africano para guiar el desarrollo de los años inmediatamente posteriores al apartheid. Aunque los contextos de estos dos casos difieren en aspectos importantes, ambos revelan conflictos similares entre propósitos morales y restricciones políticas y económicas, en el contexto de proyectos del mejoramiento de calidad de vida. El artículo concluye con algunas reflexiones sobre la tensión entre particularidad y universalidad en los planteamientos sobre el desarrollo.

\section{Dimensiones morales de algunos problemas del desarrollo}

Los juicios morales (o éticos) se ocupan de lo que es bueno o malo, lo que está bien o mal: lo que debe o no debe hacerse. Bueno y malo generalmente se aplican a las personalidades o estilos de vida de la gente, mientras que bien y mal se aplican a sus acciones. Sin embargo, estos términos tienen un uso muy general en la lengua inglesa ( $\mathrm{y}$ española), de modo que bueno o malo se pueden referir a una actuación musical o a una comida, por ejemplo, mientras que bien o mal pueden describir la manera en que se tocaron unas notas o al hecho de elegir una comida. Si bien no pueden trazarse límites firmes, referirse a los juicios sobre lo que está bien o mal como juicios morales o éticos, les otorga una fuerza especial. Pueden carecer del imperativo absoluto de los mandamientos establecidos por algún dios o poder terrestre al que se debe completa obediencia (excepto a aquellos que reconocen tales fuentes de poder), pero son de un orden distinto a la ejecución técnica o al gusto. Así, se esperaría que las propuestas de desarrollo cimentadas en argumentos morales tuvieran mayor convicción que los argumentos basados en convenciones sociales, opiniones profesionales o los caprichos de un gobernante, por ejemplo. 
La significancia $-\mathrm{y}$ dificultad- del juicio moral en el contexto del desarrollo puede ejemplificarse brevemente regresando a los fundamentos de Friedmann. La idea de "derechos" implica el derecho que tienen los individuos (o grupos) a algo, lo cual conlleva obligaciones en cuanto a lo que algunos (otros) deben o no deben hacer, es decir, asegurar que impere el bien o impedir que se infrinja. Sin embargo, no es necesariamente obvio quiénes podrían ser estos otros, como se explicará más adelante: ¿̇Se trata de otros individuos, como los miembros de la familia, de una comunidad local, de alguna agencia del estado? Saber quiénes son derechohabientes también es un problema, como lo implica la distinción entre derechos humanos y derechos ciudadanos: todos los seres humanos califican para los primeros, mientras que los segundos son exclusivos de los miembros de jurisdicciones políticas particulares. La noción de florecimiento humano evoca alguna elevada condición del ser, lo cual produce variadas y a veces opuestas especificaciones sobre qué significa vivir bien. Esto da lugar a la cuestión de si se puede decir algo universal del florecimiento humano, más allá de la especificidad geográfica e histórica de los distintos lugares, tiempos y culturas.

El desarrollo en tanto progreso o mejoramiento humano, y los planes que lo promueven, evidentemente implican a personas particulares, en sitios particulares y momentos particulares, capaces de mejorar sus vidas de acuerdo con su concepción de desarrollo. En este sentido, el desarrollo es necesariamente contextual. Pero esta concepción no tiene que ser del todo, y ni siquiera en gran medida localista; de hecho, cuanto más los medios de comunicación aumentan el conocimiento de las vidas de otras personas en otros sitios, globalizando por lo menos algunos aspectos de la cultura, tanto más pueden parecerse las aspiraciones de la gente. La interacción, o tensión, entre el universalismo de un punto de vista cosmopolita y el relativismo de la particularidad local es lo que subyace a la dificultad, o desafío, de aproximarse al desarrollo en el moderno estilo de teoría general sin olvidar la diferencia contextual destacada por el pensamiento posmoderno. Este artículo espera demostrar que, como ocurre en otras disyuntivas o dualidades, la distinción entre lo particular y lo universal del desarrollo se disipa con una investigación más cercana.

\section{Necesidades bumanas}

Las necesidades humanas son un punto de partida obvio para la teoría y práctica del desarrollo. La noción de necesidad está imbuida de mayor urgencia que los simples deseos o ganas de algo. A menudo reviste la fuerza moral de una autoridad objetiva externa a la cual el individuo está vinculado, como cuando un doctor asegura que un paciente necesita un tratamiento particular, en oposición a la subjetividad de un individuo que asegura necesitar un trago o algún otro objeto de deseo personal. Las necesidades particularmente urgentes a veces se denominan básicas, y la satisfacción de las necesidades básicas de la gente se considera una prioridad para el proceso de desarrollo. A la idea relativista de que las necesidades humanas son contextuales, exclusivas de lugares y tiempos particulares, se opone el argumento universalista de que todas las personas comparten las mismas necesidades básicas.

Sin embargo, los intentos por definir conjuntos de necesidades humanas universales (o básicas) revelan diferencias. Kekes (1994:49), por ejemplo, identifica como independientes de contexto los requerimientos mínimos del bienestar humano:

Estos requisitos están definidos por necesidades universalmente humanas, históricamente constantes y culturalmente invariantes creadas por la naturaleza humana. Muchas de estas necesidades son fisiológicas: alimento, vivienda, descanso y demás; otras necesidades son psicológicas: compañía, esperanza y ausencia de horror y terror en la vida personal, entre otras; aún otras necesidades son sociales: orden y predictibilidad en la sociedad, seguridad, cierto respeto, etc.

Kekes se refiere a la satisfacción de estas necesidades como valores primarios, en oposición a los valores secundarios, que derivan de la satisfacción de necesidades que varían con las tradiciones $e$ ideas de lo que es un buen nivel de vida. Compárese esto con un punto de vista más restrictivo (O'Neill, 1991:279):

No causa controversia que los seres humanos necesitan alimento apropiado, casa y vestido adecuado a su clima, agua limpia e higiene y algún cuidado paterno y de salud. Cuando no se satisfacen estas necesidades básicas la gente a menudo se enferma y muere prematuramente. En cambio, causa controversia la y muere prematuramente. En cambio, causa controversia la
necesidad humana de compañía, educación, politica y cultura, o alimento espiritual, pues por lo menos varias vidas largas y no evidentemente atrofiadas se han vivido sin estos bienes. 
De modo que la compañía, entre otras cosas, puede o no ser una necesidad esencial. Así, lo que se requiere para llevar una vida humana satisfactoria está evidentemente sujeto : a interpretaciones alternativas.

Una posibilidad es definir las necesidades humanas universales en un sentido mínimo, simplemente en relación con la supervivencia física. Esto es aún más restrictivo que la formulación de O'Neill, que pretende evitar la muerte prematura más que permitir la supervivencia diaria, para lo cual los requerimientos básicos son los mismos que para cualquier criatura no humana. El argumento de una definición más amplia, que incluye cuestiones como educación y alimento espiritual, descansa sobre propuestas quie toman en cuenta la naturaleza distintiva del ser humano.

Doyal y Gough (1991) proporcionan un análisis particularmente completo del concepto de necesidad humana. Se acercan más a Kekes que a O'Neill al asegurar que nuestra constitución mamífera determina la necesidad de factores como el alimento y calor necesarios para sobrevivir y mantener la salud, mientras que nuestras actitudes cognitivas y experiencias infantiles moldean las necesidades de relaciones cercanas y de apoyo, entre otras (Doyal y Gough, 1991:37). Su hostilidad al relativismo se expresa en la noción de que todas las personas comparten una necesidad obvia: evitar daño serio. Esto implica más que el fracaso en la supervivencia física: la participación deficiente en el medio social predominante. De esto se siguen dos necesidades básicas: salud física, para continuar viviendo y funcionando eficazmente, y la autonomía o habilidad personal suficiente para tomar decisiones informadas en cuanto a qué hacer y cómo hacerlo en un contexto social determinado. Las necesidades básicas a su vez requieren la satisfacción de ciertas necesidades intermedias: nutrición adecuada, vivienda, seguridad y educación, entre otras. Los satisfactores, es decir, los bienes y servicios que cubren estas necesidades intermedias, sí pueden ser particulares de cada cultura, en oposición a la universalidad de las necesidades mismas. Esto es parecido al planteamiento de Sen (1992) sobre la pobreza, a la que considera absoluta o universal en tanto limita el funcionamiento de la gente, pero relativa en relación con las comodidades necesarias para aliviarla.

El universalismo de Doyal y Gough se logra con lo general de la noción de evitar daño serio. Sin embargo, el énfasis en el funcionamiento dentro de un medio social determinado (culturalmente variable) subraya su idea de que la vida humana consiste en más que la simple supervivencia física o incluso la longevidad. Esta posición es apoyada por otros que aseguran derivar conjuntos de necesidades a partir de la naturaleza humana o de los requerimientos para el florecimiento humano (e.g. Brown, 1986:159; Griffin, 1986:86-87). También es interesante notar el carácter social o de relación personal (y no material) de dos ideas mínimas sobre qué significa ser bumano y no cualquier otra criatura viva: poder aparecer en público sin sentir vergüenza (de Adam Smith, ver Sen, 1992:116), y la susceptibilidad al dolor particular de la humillación (Rorty, 1989:92).

O'Neill quizás tenga razón al asegurar que se puede vivir sin evidente atrofio satisfaciendo sólo las recurrentes necesidades de la supervivencia. Pero garantizar la supervivencia generalmente implica relaciones de cooperación con otra gente; se extiende bastante más allá de la nutrición infantil y la consiguiente atención a la salud, e incluso éstas requieren instituciones sociales de mantenimiento y regulación. Cuanto más específicos seamos al definir las necesidades humanas en este sentido más amplio, tanto más difícil será sostener una posición universal, pues contextos distintos pueden requerir distintas respuestas individuales e institucionales. También hay que considerar que aquellas que pueden plantearse como necesidades humanas básicas podrían representar para las sociedades humanas existentes exigencias políticas y económicas tales que resulten inaceptables, independientemente de la fuerza de su justificación moral.

\section{Derecbos bumanos}

El paso de las necesidades humanas a los derechos humanos es muy pequeño en la teoría, aunque bastante grande en la práctica. Si hay ciertas cosas que se necesitan universalmente para vivir una vida humana, entonces seguramente todas las personas, en todas partes, las deberían tener por derecho. Sin embargo, la noción de derechos humanos (o ciudadanos) plantea importantes y difíciles problemas en cuanto a qué son (dependiendo, por ejemplo, de si las vidas que sostienen deben ser mínimas, decentes o florecientes), cómo deben priorizarse, dónde se aplican, quiénes son derechohabientes y quiénes tienen las consiguientes obligaciones.

Friedmann (1992:10) continúa su fundamentación del derecho material y político refiriéndose a la Declaración Universal de Derechos Humanos adoptada en 1948 por la Asamblea General 


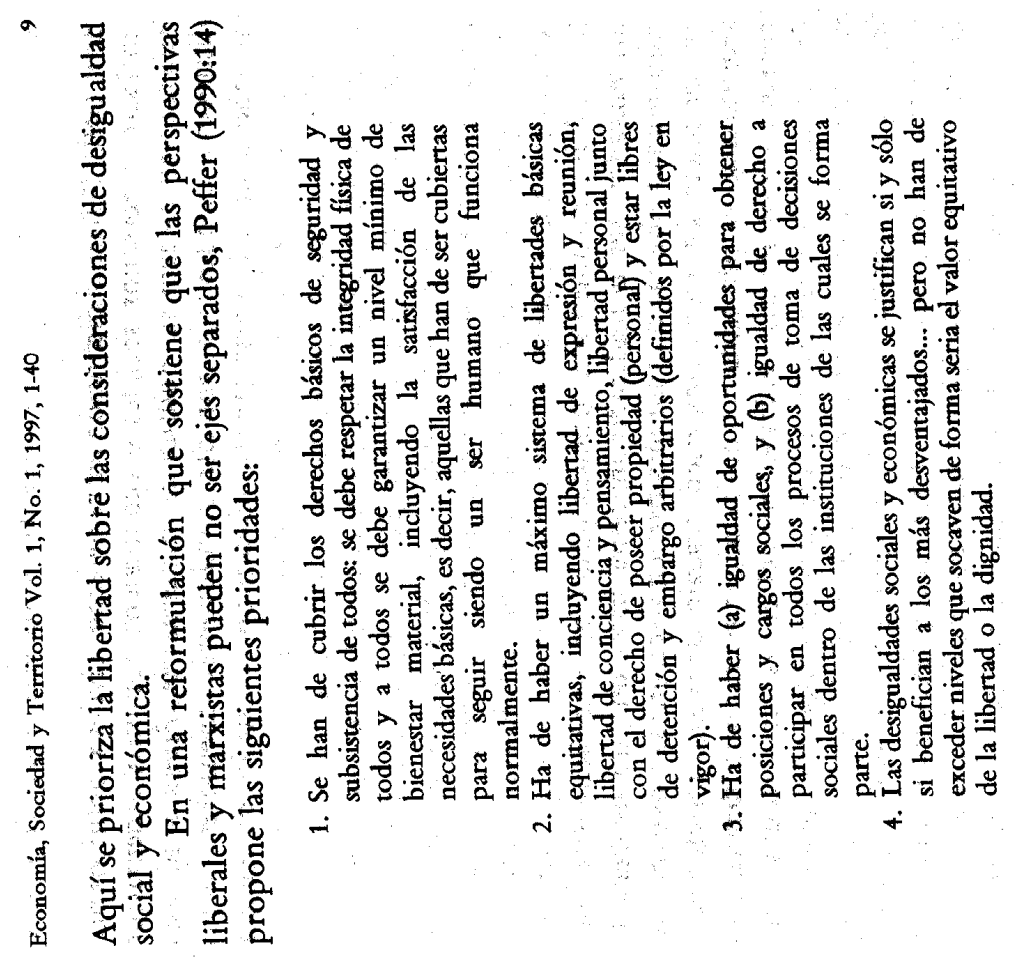

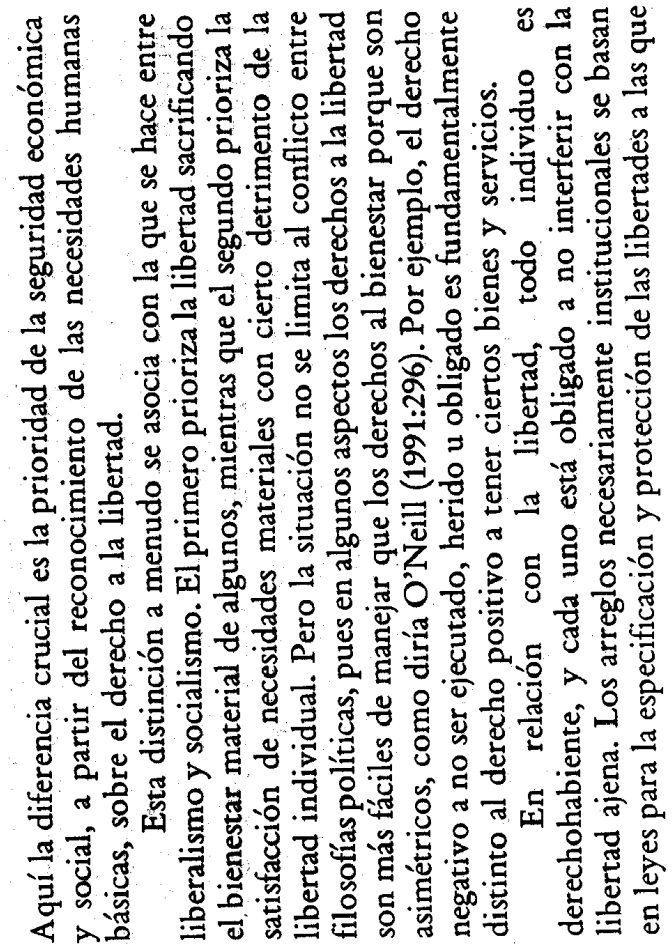

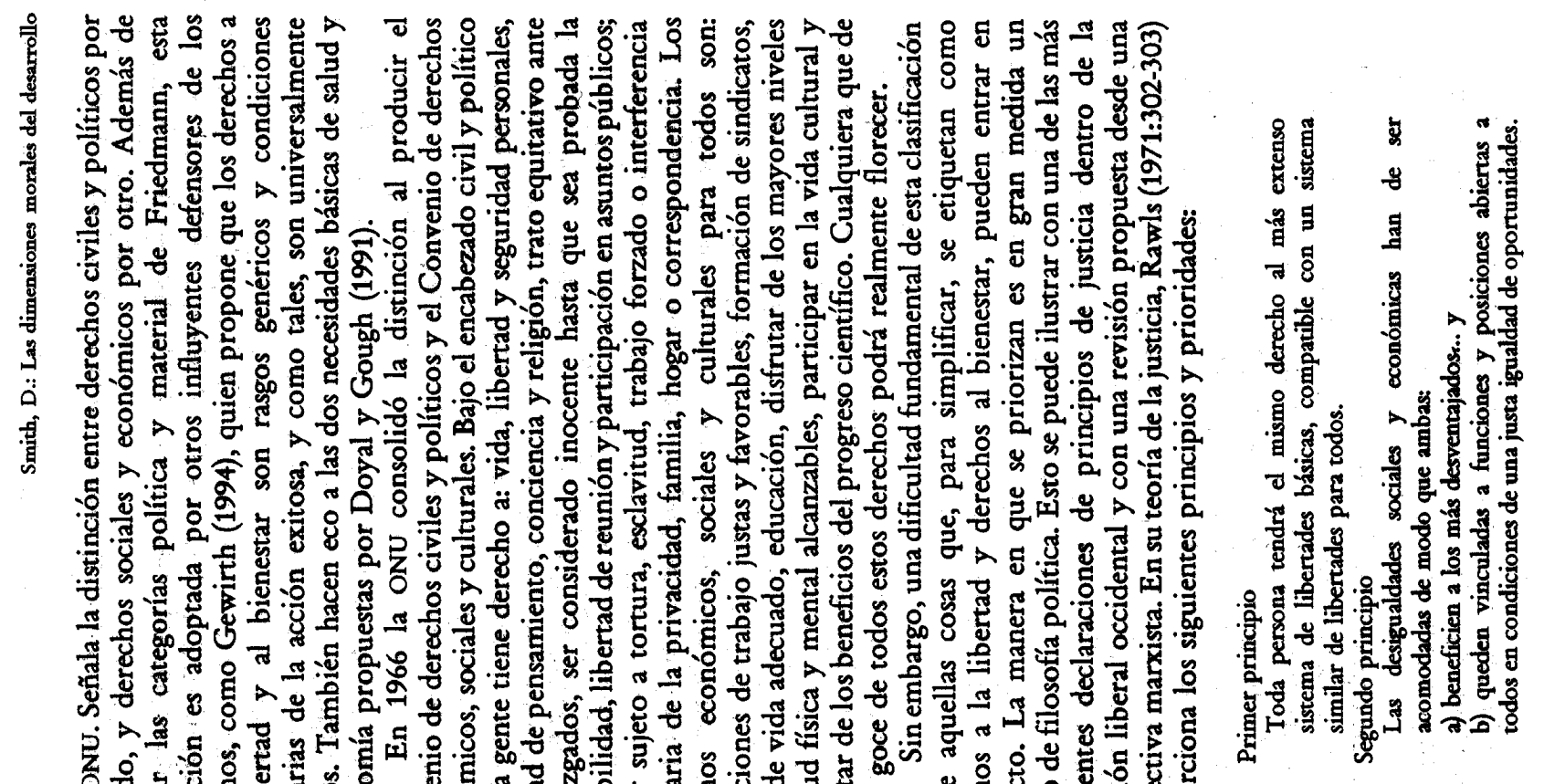

$\infty$ 卞 
cada individuo tiene derecho. En relación con los derechos al bienestar, sin embargo, aunque los derechohabientes son evidentemente todas las personas en tanto individuos, no está claro quién está obligado a satisfacer las exigencias implicadas. Por ejemplo, si todos tienen derecho al alimento, vestido $y$ vivienda necesarios para sobrevivir, y a otras cosas que pueden ser necesarias para florecer, ¿quién (o qué agencia) está obligado a proporcionarlas? ¿Han de ser otros individuos o grupos particulares (como la familia o comunidad local), o un gobierno local, o el gobierno nacional o alguna agencia internacional? Estas cuestiones son las que vuelven los derechos al bienestar tanto más difíciles de definir, y de exigir, que los derechos a la libertad, incluso sin una justificación filosófica que priorice una $u$ otra.

Hay otras razones por las cuales es probable que en la práctica los derechos a la libertad se defiendan antes que los derechos al bienestar. Algunas son económicas, en relación con el costo de proporcionar de hecho los bienes y servicios necesarios para implementar los derechos al bienestar. Algunas son políticas, y reflejan como filosofía prevaleciente el liberalismo y el actual alejamiento de los beneficios universales asociados con un estado benefactor. Así, mientras a la mayoría de la gente en la mayor parte del mundo se le garantizan por ley (aunque no necesariamente se defiendan en la práctica) algunas libertades elementales, esto deja de ser cierto incluso para los más básicos medios de subsistencia. Esto nos lleva a preguntarnos por el grado de libertad de que gozan algunas personas, si su principal preocupación en la vida es sobrevivir en lugar de florecer.

\section{Justicia social}

A quién se le deben adjudicar cuáles beneficios (y cuáles cargas) particulares es un asunto de justicia social o distributiva. Así, las distintas especificaciones de derechos planteadas por Rawls y Peffer están contextualizadas en forma de teorías de justicia. También los arreglos institucionales responsables de la producción y distribución material, incluyendo los derechos de propiedad y otras relaciones sociales de producción, pueden ser sujetos del discurso de la justicia social. El problema aquí, tanto para el "desarrollo" como para cualquier empresa humana que deba determinar quién obtiene qué, dónde y cómo, es que hay distintas y a veces opuestas aproximaciones a la justicia social (ver revisiones en Brown, 1986; Campbell, 1988; Kymlicka, 1990 y Smith, 1994, caps. 3 y 4).

Antes de Rawls (1971) el pensamiento en torno a la justicia social estaba dominado por el utilitarismo. Esta teoría moral general sostiene que la gente debe actuar de modo que maximice la suma total de felicidad, satisfacción, bienestar o alguna cualidad humana semejante. Mientras se logre maximizar la utilidad, la distribución no importa, a menos que se asuma una utilidad marginal decreciente (en dinero, por ejemplo), de modo que el bienestar agregado aumente por las transferencias de ricos a pobres. Por lo tanto, el utilitarismo puede condonar situaciones altamente desiguales, mientras que el enriquecimiento de los ricos y el empobrecimiento de los pobres no reduzca el bienestar global. El desafío de Rawls al utilitarismo fue en gran medida igualitario, aunque sujeto al llamado principio de diferencia (establecido en (b) en su segundo principio, citado más arriba), que permite la desigualdad mientras sea en beneficio del grupo más desventajado de la sociedad.

El libertarismo, por su parte, es indiferente a la distribución mientras que la gente sea libre de utilizar como desee propiedades adquiridas de manera justa, y mientras exista la misma libertad para todos (e.g. Nozick, 1974). El marxismo concibe la moralidad y la justicia como aspectos internos de sociedades o modos de producción particulares, a cierto nivel, aunque asegura el derecho más amplio de la fuerza de trabajo a no ser explotada y privada del valor de su producto (para una discusión más amplia al respecto ver, por ejemplo, Peffer, 1990). Algunas versiones del feminismo se oponen a la teoría moral predominante de la tradición universalista, y exigen aproximaciones contextuales o de relación atacando además la hegemonía masculina y las estructuras patriarcales de dominación y represión (ver por ejemplo Benhabib, 1992; Hekman, 1995). El comunitarismo considera a la justicia simplemente como una virtud correctiva que entra en juego cuando se derrumban los valores comunitarios de mutualidad y reciprocidad (ver Sandel, 1982). Finalmente, los pensadores posmodernos consideran que tal diversidad de perspectivas es inconmensurable y socava la posible superioridad de cualquier teoría general de justicia social.

Existe, sin embargo, una idea de que todas las teorías actuales sobre la sociedad justa, más que basarse en valores últimos opuestos, tienen el mismo fundamento: la igualdad (Kymlicka, 1990:4-5). Todas requieren, en algún aspecto importante, que la gente sea tratada con igualdad. Así, además del forzado igualitarismo del liberalismo de Rawls, el utilitarismo requiere que cada individuo 


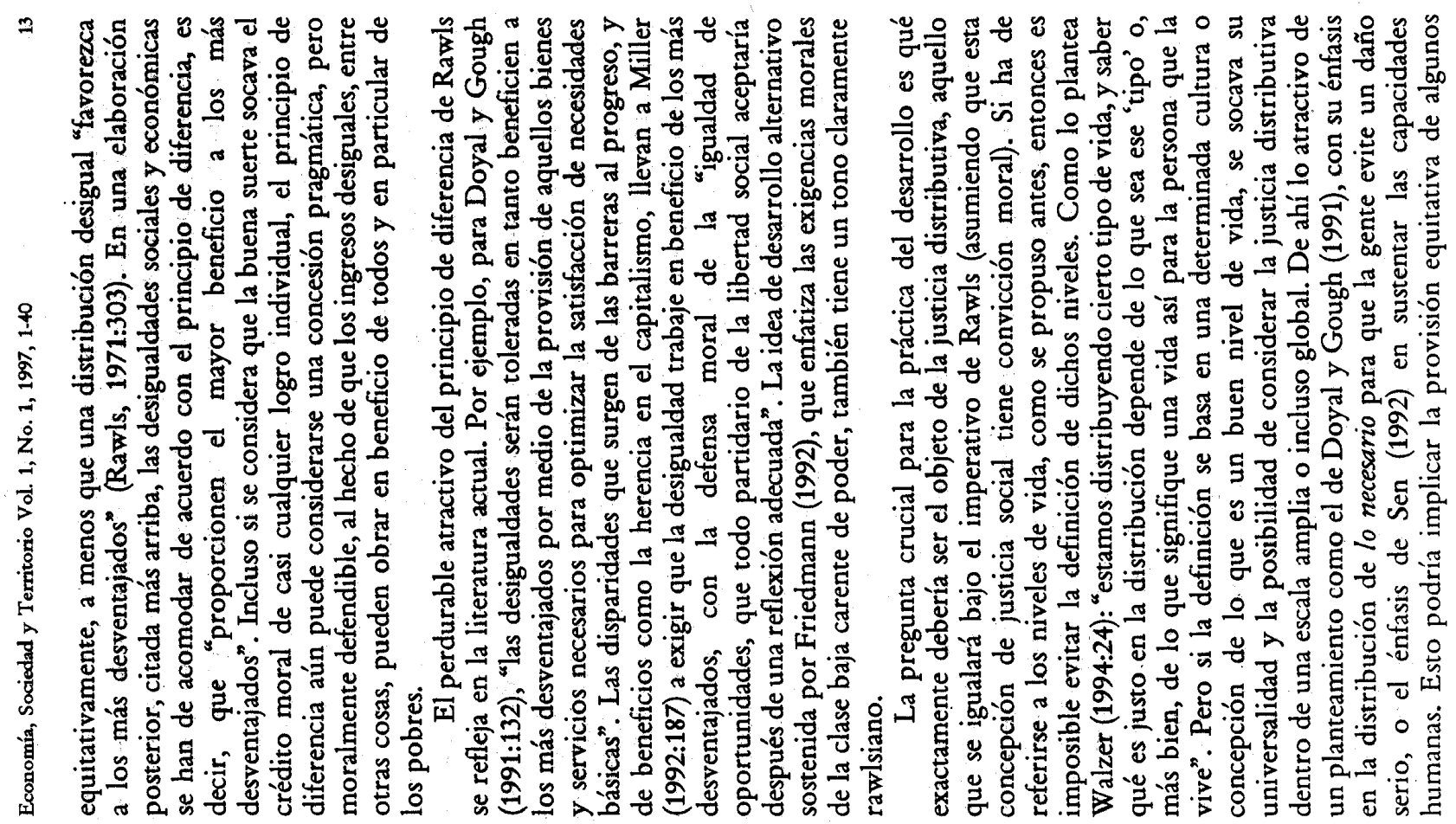

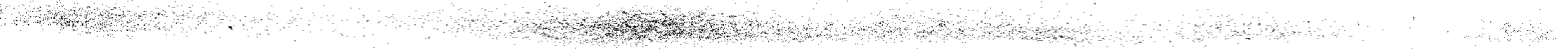

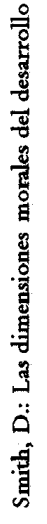

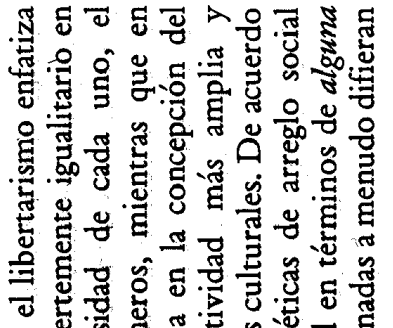

অ유.

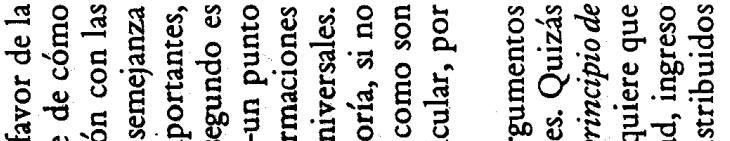

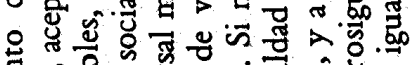

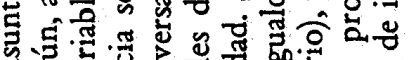

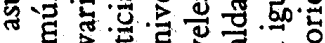

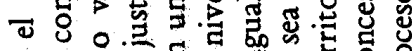

군

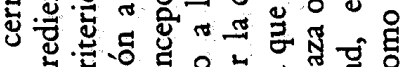

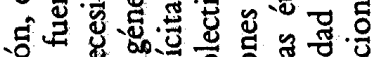

净 \&

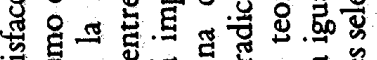

ช.

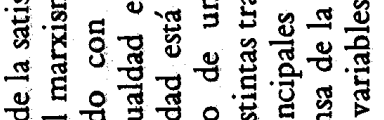

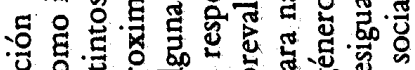

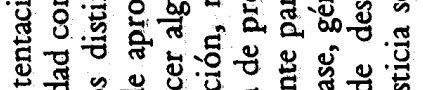

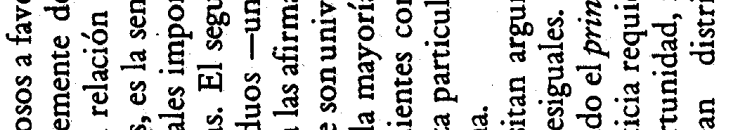

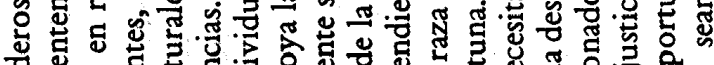

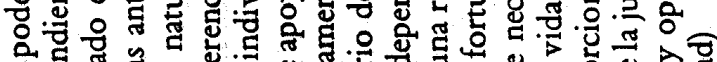

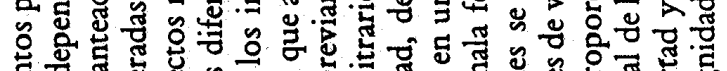

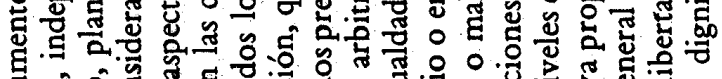

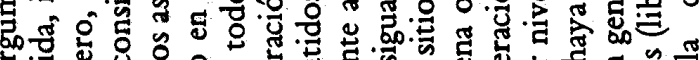

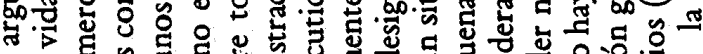

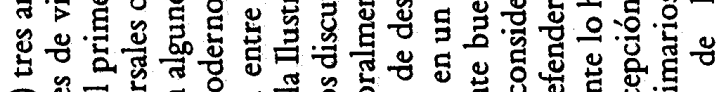

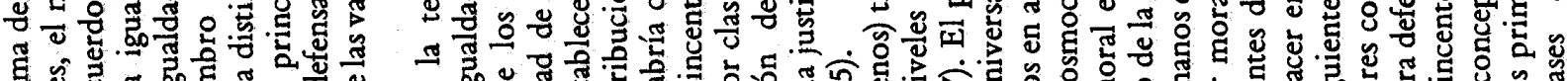

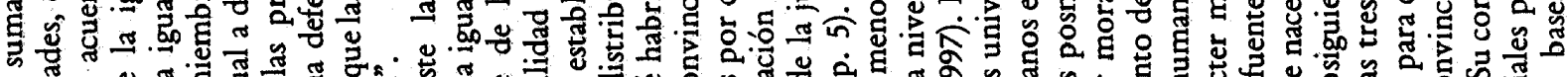

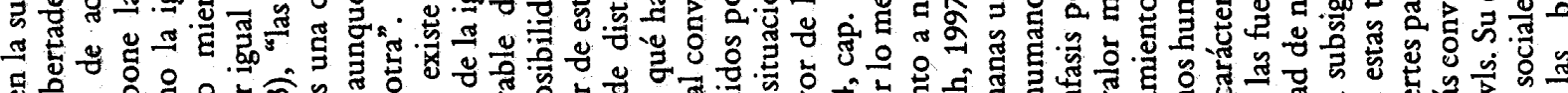

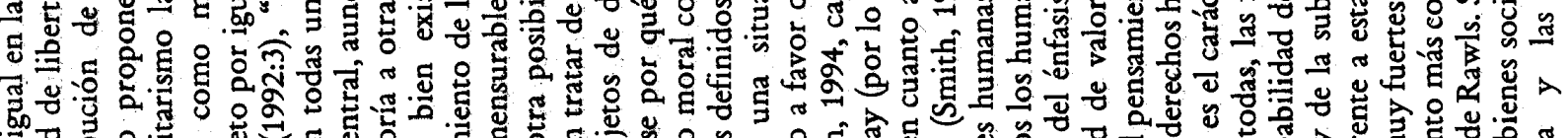

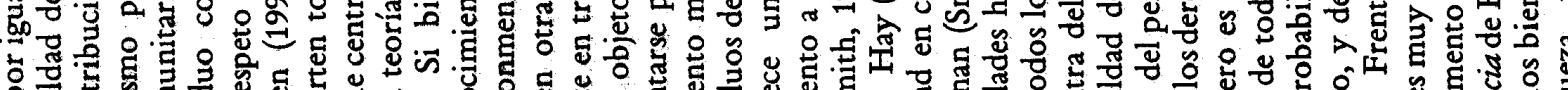

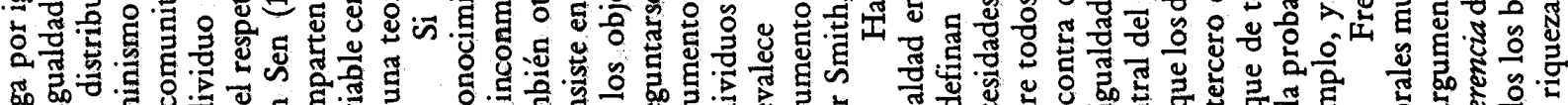

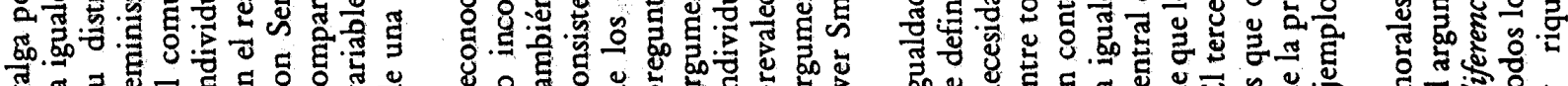

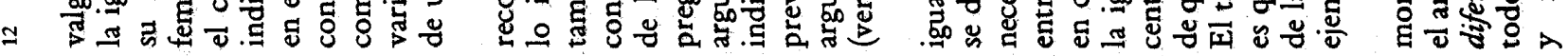


bienes y serviciơs, poniendo los demás productos de la sociedad ya sea en la competencia mercantil (en el capitalismo), o en una asignación central de acuerdo con algún tipo de prioridades colectivas (en el socialismo). Sin embargo, igualar los recursos para evitar un daño serio a escala global dejaría poco lugar a las desigualdades substanciales que se requieren para sostener indulgencias particulares. En otras palabras, dados los límites de los recursos globales, satisfacer las necesidades básicas de todos aquí y ahora, sin tomar en cuenta la provisión para las generaciones futuras, dejaría poco lugar para la desigualdad.

Definir calidad de vida no es en absoluto la única dificultad de una práctica del desarrollo guiada por el igualitarismo. También es importante tener en mente distinciones como la de igualar entradas (e.g. las inversiones), productos (e.g. servicios particulares) y resultados (los efectos sobre las vidas de la gente), o la de igualar oportunidades, capacidad de aprovecharlas y sus resultados en relación con alguna concepción de nivel de vida. Estas distinciones, y las relaciones entre ellas, tendrán todas su particularidad local, comunitaria o nacional, requiriendo a veces la desigualdad respecto a una (e.g. invertir en servicios creadores de capacidades) para promover la igualdad respecto a otra (e.g. oportunidades reales). Sin embargo, es probable que el principal obstáculo sea la hostilidad ideológica al igualitarismo en sí, a pesar de los puntos morales a su favor.

\section{Espacio geográfico: sitio, territorio, fronteras y distancia}

El espacio geográfico está profundamente implicado en varios aspectos morales del desarrollo. El espacio es una dimensión importante de la inequidad asociada al desarrollo desigual, término que a menudo implica la desigualdad espacial. La variada dotación de recursos sobre la tierra, las capas diferenciadas de inversión en capacidad productiva e infraestructura, y la organización espacial de los flujos de capital, bienes y comunicaciones, son los factores en mayor medida responsables de los patrones de desarrollo que la planeación busca modificar. Todo esto se comprende lo suficiente como para no requerir mayor elaboración.

Menos familiar es el papel del espacio en los tres fundamentos de Friedmann: derechos humanos, derechos ciudadanos y florecimiento humano. La importancia del territorio en la perspectiva moralmente informada de Friedmann es tal, que vale la pena citarla. En respuesta a la tendencia de los economistas de ignorar el análisis territorial, Friedmann (1992:40) dice:
Nos interesa la territorialidad no por alguna oscura metafísica espacial, sino porque la gente habita estos espacios, y es esta gente de carne y hueso quien padece los altos y bajos de la economía. La gente no es una categoría abstracta de fuerza de trabajo que se mueve mecánicamente en el momento correcto y en las proporciones correctas hacia cualquier sitio donde surjan oportunidades económicas. Son seres sociales, vinculados, que viven en familias, hogares y comunidades y que interactúan con vecinos, parientes, amigos y conocidos. A lo largo del tiempo la gente que habita sitios particulares produce patrones típicos de habla y prácticas rituales y sociales con las cuales se siente cómoda, "como en casa".

El desarrollo alternativo implica que la gente desventajada adquiera poder, $y$ la primera de varias bases del poder social identificadas por Friedmann (1992:67-68) es un espacio vital defendible:

Como base territorial de la economía familiar, el espacio vital defendible incluye el espacio físico donde los miembros del hogar cocinan, comen, duermen y aseguran sus posesiones personales. En un sentido más amplio, se extiende más allá del espacio llamado "hogar" hacia el vecindario inmediato, donde se llevan a cabo la socialización y otras actividades vitales, principalmente en el contexto de la economía moral de las relaciones no mercantiles.

Insiste en la territorialidad del desarrollo alternativo por las siguientes razones (Friedmann, 1992:133):

El territorio coincide con el espacio vital, y la mayoría de la gente busca ejercer cierto grado de control autónomo sobre estos lugares.

La territorialidad existe a todas las escalas, de la más pequeña a la más grande, y somos simultáneamente ciudadanos de varias comunidades territoriales a diferentes escalas: nuestras lealtades siempre están divididas.

El territorio es una fuente importante de vínculos humanos: crea un bien público, vinculando el presente con el pasado en tanto fundamento de las memorias comunes (historia) y con el futuro en tanto destino común.

La territorialidad nutre una ética de cuidado $y$ atención de nuestros conciudadanos y del medio que compartimos con ellos. 
Estos pasajes enfatizan el rico y variado papel que desempeña el territorio en los asuntos humanos. En primer lugar, tener un sitio en el mundo es una necesidad humana tan básica como cualquier otra: la gente debe ocupar un espacio. El espacio particular al cual la gente regresa regularmente cubre necesidades de supervivencia física y seguridad, además de las necesidades psicológicas de relación con otra gente. El lugar se liga estrechamente con la identidad y cultura individuales y grupales de las personas, y se vuelve parte de lo que las hace ser lo que son, lo que fueron sus antepasados y lo que serán sus descendientes. En esto hay fuertes ecos del comunitarismo, así como un reconocimiento de là ética del cuidado que ha sobresalido en algunas críticas y extensiones feministas del pensamiento moral predominante (e.g. Tronto, 1993; Hekman, 1995). El apego al territorio es esencial para una concepción amplia del florecimiento humano que incorpore aspectos sociales, económicos y políticos de la vida.

Ante todo esto se podría agumentar que las diversas necesidades humanas asociadas al territorio son universales, de donde se desprenderían algunos derechos universales. Algunos ejemplos serían el derecho positivo al terreno necesario para el hogar y la comunidad, y el derecho negativo a que los asentamientos individuales y colectivos no sean destruidos sin un adecuado proceso de ley y una muy buena causa. La cuestión es que en la práctica estos derechos, como otros mencionados antes, están lejos de ser universales. Esto ocurre porque los ciudadanos de algunos territorios (jurisdicciones políticas locales y nacionales) no tienen disposición, y quizás tampoco posibilidad, de cumplir con las obligaciones que estos derechos implican. Sin disposición, a causa del tipo de obligaciones implicadas que pueden amenazar los derechos de propiedad de aquellos con bastantes bienes y poder político. Sin posibilidad, porque incluso un Estado fuertemente igualitario y redistributivo puede no tener los recursos suficientes para proporcionar derechos de bienestar que incluyan vivienda y vecindarios decentes y seguros para todos.

Esto nos lleva a otro importante conjunto de problemas morales, en cuanto al derecho que tienen aquellos con la buena suerte de habitar cierto territorio y obtener beneficio exclusivo (literalmente) de sus recursos, ya sean naturales o producidos por la actividad humana. Un derecho tal podría restringir el derecho de las personas a moverse libremente de un sitio a otro en busca de mejores oportunidades. Walzer (1983:31 y 63) afirma que "el principal bien que distribuimos es la pertenencia a alguna comunidad humana", y que "es sólo en tanto miembros, que hombres y mujeres pueden aspirar a compartir todos los demás bienes sociales [...] posibilitados por la vida comunitaria". Aunque un territorio particular sea vital para una comunidad, $y$ de hecho un constituyente de la identidad colectiva de las personas, no es obvio que cualquiera tiene derecho de entrada, aun si el lugar de nacimiento es cuestión de buena o mala suerte. Este asunto es un aspecto del conflicto general entre derechos locales y algún bien más amplio, o lo que a veces se describe como el dilema entre soberanía y moralidad (e.g. Beitz, 1991:246).

Los comunitaristas tienden a defender las fronteras $y$ a abogar por la cohesión y distinción cultural que supuestamente encierran. Esto a su vez puede reforzar regionalismos y sentimientos de chauvinismo local o nacional, manifiestos en la hostilidad hacia distintos tipos de extranjeros. De ahí que generalmente se priorice la soberanía y exclusividad territorial sobre la libertad de desplazamiento (en Bader, 1995, aparece un resumen de los debates recientes sobre la libertad de desplazamiento en la teoría moral, y en Black, 1996, uno sobre inmigración y justicia social). La simpatía común hacia los asilados políticos, a diferencia de aquellos extranjeros llamados casi peyorativamente migrantes económicos, refleja una poderosa moralidad del derecho (o no derecho) de entrar $y$ permanecer en un territorio ajeno.

Un último asunto que se puede abordar, sólo brevemente, es el alcance espacial de la beneficencia o responsabilidad. En breve, ¿qué tanto debemos cuidar de los demás? Por un lado está la restringida responsabilidad hacia los más cercanos y más queridos, reflejada en la ética parcialista de cuidar de "los tuyos", ya sean parientes, miembros de la misma comunidad local o compatriotas. Por otro lado está la propuesta universalista de que debemos a los desconocidos distantes la misma consideración que a la gente cercana que nos rodea. Esto no es sólo un punto de debate entre filósofos de la moral, pues la manera en que se responda este dilema en la práctica tiene una importante repercusión en asuntos como el grado y alcance de la ayuda de países ricos a países pobres.

Marilyn Friedmann (1991) cristaliza los problemas implicados aquí. La parcialidad parece ser un sentimiento humano natural, esencial para la integridad personal y para un buen nivel de vida, pero se contradice con una de las tradiciones dominantes de la filosofía moral moderna: la imparcialidad, el trato por igual a todos los que estén bajo las mismas circunstancias. Señala que a veces los más necesitados de cuidado y atención parciales (e.g. las relaciones 
locales) pueden no recibirlos porque su familia, amigos o vecinos son pobres y tienen las mismas necesidades: parte de la realidad del desarrollo espacialmente desigual. La capacidad desigual para cuidar a la gente allegada reproduce, y quizás exacerba, los ya existentes patrones espaciales de desarrollo desigual. De esto se sigue un argumento a favor de una distribución más equitativa de lo necesario para prodigar cuidados, cosa que suena como los requisitos de la imparcialidad.

Esto nos lleva de regreso al argumento de la justicia social como igualación. Los laudables sentimientos humanos expresados en estrategias como cuidar de la gente cercana o atender a la comunidad adquieren fuerza moral al punto de que se igualan a la capacidad de cuidar y a la posibilidad efectiva de ser cuidado. He ahí, de nueva cuenta, el poder de lo que Corbridge (1993) considera un argumento a favor de una idea mínimamente universal de la necesidad humana y de nuestras consiguientes responsabilidades, cubriendo las necesidades de los desconocidos distantes por derecho. En referencia al grado en que nuestras vidas están cada vez más conectadas con las de personas distantes, en conjuntos de relaciones económicas y políticas globalizadas, se señala que no existe razón lógica por la cual las fronteras morales habrían de coincidir con las de nuestra comunidad cotidiana. De modo que "para cumplir con un compromiso activista con el localismo político o de desarrollo, no es necesario excluir una política más amplia de desarrollo formada por las preocupaciones 'abstractas' de la filosofía moral" (Corbridge, 1993:466).

\section{El caso del Reino Unido}

Los casos de estudio nacionales pueden ayudarnos a revelar algo, tanto de la particularidad como de la generalidad, de los aspectos morales de los problemas del desarrollo. En este caso se resume la reciente evidencia de la creciente desigualdad en Gran Bretaña, tendencia que comparte con la mayoría de los países industrializados. Luego se revisan dos aproximaciones bastante distintas a la cuestión del derecho. Se concluye con un breve examen de algunas restricciones a la búsqueda de justicia social.

\section{Desigualdades en ingreso y riqueza}

En una investigación nacional detallada (Rowntree, 1995), la fundación Joseph Rowntree reveló que la desigualdad de ingresos en el Reino Unido había aumentado rápidamente entre 1977 y 1990 , alcanzando el punto más alto desde la segunda guerra mundial. Entre 1977 y 1992 el 20-30\% de la población más pobre no logró beneficiarse del crecimiento económico, lo contrario a la tendencia posterior a 1945; el 10\% más pobre se empobreció aún más, en términos relativos y absolutos. A partir de 1977 se triplicó la proporción de población con menos de la mitad del ingreso nacional promedio. Así, en las últimas dos décadas se ha visto un cambio dramático a partir de las tendencias más igualizadoras de los años sesenta y setenta.

En cuanto a la riqueza, las grandes desigualdades nacionales heredadas se estrecharon rápidamente hasta mediados de los setenta cuando se estabilizaron. El 10\% más rico de la población poseía en 1976 50\% de la riqueza total, y en 1992 aún 49 por ciento. El 50\% más pobre de la población aún posee sólo $8 \%$ de la riqueza total; la mitad de los hogares tiene un activo líquido (no en inmuebles) menor a 500 libras esterlinas (más o menos 6,000 pesos mexicanos al tipo de cambio de 1997). La riqueza todavía tiene una distribución mucho más desigual que el ingreso.

El reporte Rowntree atribuye las crecientes diferencias a múltiples causas. Más gente se ha hecho dependiente de los beneficios de la seguridad social pública, en gran medida a causa del alto nivel de desempleo y la creciente población jubilada. La diferencia de ingresos entre los beneficiarios y los trabajadores se ha ampliado. Entre estos últimos, los salarios por hora para los peor pagados apenas han variado en términos reales desde 1978, mientras que los salarios medios han aumentado $38 \%$ y los altos $50 \%$. Otros factores incluyen un aumento tanto de familias con dos miembros que trabajan, como de aquéllas con ninguno, y un aumento en el empleo por cuenta propia con ingresos relativamente bajos.

Se llama la atención hacia grupos $y$ áreas desproporcionadamente desfavorecidas. Se distingue a los pensionados y a ciertas minorías étnicas (dentro de la llamada población no blanca), así como a los niños de las familias de bajos ingresos. Se subraya el vínculo entre grupos y áreas: una gran proporción de grupos étnicos con ingresos bastante inferiores al promedio nacional vive en zonas desprovistas, y los niños de familias pobres generalmente viven en barrios donde la mayoría de 
la población también es pobre y las zonas tienen bajos niveles de provisión de servicios y oportunidades de desarrollo. Otras observaciones sobre la geografía de la situación incluyen el hecho de que algunas partes del país parecen atrapadas en una espiral de deterioro, mientras crecen las diferencias substanciales entre barrios afluentes y carentes. Como la vivienda pública está altamente nucleada, la polarización de los grupos de ingreso por ocupación lleva a una concentración de gente de bajos ingresos en vecindarios particulares. Así, el reporte Rowntree (1995) considera que para muchas áreas del Reino Unido los estándares y oportunidades de vida de los más pobres son inaceptablemente bajos para una sociedad tan rica como la británica.

La investigación Rowntree buscaba los efectos sociales generales de los cambios distributivos. Concluía que, aunque sería posible justificar una creciente desigualdad con la idea de que los efectos benéficos del crecimiento económico aumentarían los niveles de vida de los más pobres, no hay evidencia de que esto haya ocurrido en Gran Bretaña. No hay señal de derrame de riqueza ni de una igualdad promotora del crecimiento. Así, lo observado no pasó la prueba de Rawls del principio de diferencia de la justicia social.

El autor de una crítica a las instituciones económicas británicas (Hutton, 1995) sugirió que hay desigualdad porque los ricos y el Partido Conservador así lo quieren, y porque "son muy débiles las fuerzas morales y sociales que se les oponen" (The Guardian, 13 de febrero, 1995). Los responsables del reporte Rowntree apelaron al egoísmo de la clase alta, señalando que la proximidad física de ricos y pobres en las ciudades y pueblos británicos era una de las razones por las que los ricos debían reconocer que la creciente desigualdad y fragmentación social les podía hacer daño. Se los había citado así: "Mas allá de argumentos morales o sentimientos de altruismo, todos comparten un interés por la cohesión social. A medida que crece la brecha entre ricos y pobres, los problemas de los grupos marginales rezagados repercuten en la mayoría acomodada" (The Guardian, 10 de febrero, 1995). De modo que tanto moralidad como prudencia parecían apuntar en la misma dirección: las ventajas colectivas de la igualdad, o sea, del angostamiento de la brecha entre ricos y pobres.

\section{La Carta de los Ciudadanos}

Cuando en noviembre de 1990 John Major remplazó a Margaret Thatcher como dirigente del Partido Conservador y; por lo tanto, como primer ministro, una de sus primeras iniciativas políticas fue la Carta de los Ciudadanos. Los años ochenta bajo Thatcher se caracterizaron por la reorganización institucional -privatización o comercialización del sector público. La Carta de los Ciudadanos se centra en una detallada especificación de los derechos o garantías individuales en relación con la provisión de varios tipos de servicios. John Major explica la Carta (The Citizen's Charter, 1994, p. 3) como sigue:

$$
\begin{aligned}
& \text { Mi objetivo con la Carta de los Ciudadanos es sencillo pero } \\
& \text { ambicioso: quiero elevar el nivel de los servicios públicos, y } \\
& \text { quiero que los servicios públicos respondan mejor a las } \\
& \text { necesidades y deseos de la gente que los usa. A través de la } \\
& \text { Carta de los Ciudadanos quiero otorgar más poder a los } \\
& \text { ciudadanos para que obtengan de los servicios la calidad que } \\
& \text { merecen. La Carta de los Ciudadanos no implica más acción } \\
& \text { estatal. Implica el derecho de los ciudadanos a estar informados } \\
& \text { y hacer sus propias elecciones. }
\end{aligned}
$$

El tono parece dotar al ciudadano de poder contra el Estado, enfatizando la importancia de una elección individual bien informada. El equilibrio del poder pasará de las instituciones y personal que proporcionan servicios, a los usuarios individuales, con los derechos y exigencias de autonomía profesional posiblemente conferidos.

Lo más que el texto se acerca a una justificación moral para la Carta de los Ciudadanos es decir que los servicios públicos afectan a diario las vidas de la gente, cubren algunas de sus necesidades más básicas y a menudo son más requeridos por los miembros más vulnerables de la sociedad. Tiène ecos de algunos temas actuales del discurso del desarrollo y de la justicia social, en particular el énfasis en las necesidades básicas y el reconocimiento (casi rawlsiano) de la posición de los más desfavorecidos. Sin embargo, la parte substancial es evidentemente la de los derechos de la ciudadanía nacional.

En cuanto a la estrategia, queda claro que se buscará el valor monetario, continuando con las políticas (thatcherianas) de sujetar los servicios públicos a la competencia, bajo el supuesto de que siendo públicos son inherentemente menos eficientes que los 
privados, por lo menos mientras no se pruebe lo contrario. Se enfatiza el que los servicios públicos traten a las personas como clientes valiosos, término que vuelve a invocar los valores del sector privado. De modo que se ha descrito la Carta de los Ciudadanos como "un instrumento para la creación de una Gran Bretaña de consumidores que hacen elecciones en mercados o cuasi-mercados" (Hudson y Williams, 1994:296).

La Carta se aplica a todos los servicios públicos: escuelas, hospitales, ferrocarriles, caminos, ayuntamientos, policía y bomberos. También se aplica a los servicios privatizados, como electricidad, gas, teléfono y agua; y al correo; agencias de beneficencia, oficinas de recaudación de impuestos, juzgados y demás. Se han publicado casi cuarenta cartas independientes, especificando los criterios para cada servicio.

Un ejemplo ilustrativo es la Carta de los Pacientes (The Patient's Charter, 1995), que cubre el Servicio Nacional de Salud (National Health Service, o NHS). Aquí se distingue entre los derechos "que todo paciente recibirá en todo momento", y las expectativas, o "niveles de servicio que el NHS está tratando de alcanzar", pero que pueden no lograrse en "circunstancias excepcionales". En cuanto al acceso a los servicios de salud, los derechos incluyen: recibir atención de acuerdo no con la posibilidad de pagar, sino con la necesidad clínica; ser registrado con un MP (médico practicante) y poder cambiarlo fácilmente; recibir atención médica de emergencia en cualquier momento, y ser remitido a un especialista aceptable para el paciente cuando el MP lo crea necesario. También se establecen los derechos y expectativas específicos para los servicios de MP, servicios hospitalarios y servicios comunitarios, entre otros.

El resultado más controversial de la Carta de los Pacientes fue la publicación de datos, popularmente conocidos como tablas de liga, sobre el nivel de desempeño de cada hospital. Estas tablas cuantifican el desempeño a partir de la rapidez de la atención en consulta externa, la inmediata evaluación de pacientes accidentados o de urgencias, la priorización de pacientes cuyas operaciones se han cancelado, las altas a pacientes el mismo día de la operación y la admisión sin demora de los pacientes no urgentes (The Patient's Charter, 1994). Tales datos permiten hacer comparaciones precisas del funcionamiento hospitalario en distintos sitios. Sin embargo, el interés se centra en los tiempos de espera, que son fácilmente medibles (y posiblemente manipulables), mientras que ninguno de los indicadores se refiere a los resultados, es decir, la eficacia o conveniencia de las atenciones recibidas, que son mucho más difíciles de expresar en términos numéricos.

Así como con las tablas de liga publicadas en relación al desempeño de las escuelas (principalmente resultados de evaluaciones), los datos del sistema de salud presentan dificultades de interpretación por las condiciones locales que influyen en la efectividad de los servicios. Aunque se cuestiona seriamente la eficacia de estas tablas para mejorar el desempeño, por lo menos abren el tema de las variaciones espaciales en ciertos aspectos de la prestación de servicios, dando lugar a dudas sobre el nivel de equidad de un servicio público como el NHS, que supuestamente debe ser igualmente accesible para todos cuando y donde se necesite. En este sentido, los indicadores de desempeño sirven para monitorear un importante aspecto de la justicia social.

\section{La Comisión de Justicia Social}

La Comisión de Justicia Social se'estableció en diciembre de 1992, a instigación del fallecido John Smith (entonces dirigente del Partido Laborista). Esto marcó el quincuagésimo aniversario de la publicación de Social Insurance and Allied Services (Seguro Social y Servicios Aliados, o Reporte Beveridge), que se convirtió en la base del estado de bienestar británico. El reporte Beveridge, escrito con ánimo de reconstrucción nacional luego de que la segunda guerra mundial siguiera a la depresión de los treinta, había identificado cinco grandes males: carencia, ignorancia, enfermedad, miseria y ociosidad. Las instituciones estatales de bienestar público establecidas para combatir estos problemas, incluyendo el NHS y un amplio sistema de beneficios universales en forma de derechos de seguro social, fueron un tema de consenso político virtualmente incontrovertido durante tres décadas. La antipatía del gobierno de Thatcher hacia el sector público y sus poderosos sindicatos entró en resonancia con el giro neoconservador de la política occidental en general, de modo que una renovada fe en el libre mercado llevó a la consideración de alternativas privadas a la provisión pública. Otra cuestión importante, que ningún gobierno de ninguna tendencia ideológica podía ignorar, era el creciente costo del bienestar público, con el aumento del desempleo y de la población jubilada, a medida que parecía llegar a su fin la época de prosperidad general posterior a la guerra. 
De modo que la Comisión de Justicia Social se estableció en un contexto económico, político y social bastante distinto al que prevalecía cuando nació el estado de bienestar. Algunos cambios significativos parecían inevitables, incluso desde la perspectiva de la izquierda, aunque fuera solamente porque el Estado estaba beneficiando a parte de la población que ya era capaz de cuidar de sí misma (la clase media). La idea del Partido Laborista parecía ser que reorganizar el sistema de beneficencia para alcanzar mejor a los más necesitados, sería más convincente si se cimentaba en la consideración explícita de la moralidad y justicia social, junto con la concepción informada del estado de la nación y su lugar en un mundo cambiante.

Al comienzo se reconocieron cuatro principios jerárquicos de justicia social (IPPR, 1993:i):

1. El fundamento de una sociedad libre es la igualdad de valor entre todos los ciudadanos.

2. A todos los ciudadanos les corresponde, por derecho de ciudadanía, ser capaces de cubrir sus necesidades básicas -ingreso, alimentación, vivienda, educación y salud.

3. La autonomía y dignidad personales son inherentes a la idea de igualdad de valor, aunque su cumplimiento depende del mayor acceso posible a las oportunidades.

4. Las desigualdades no son necesariamente injustas, aunque aquellas que lo sean deben ser reducidas y en lo posible eliminadas.

Estos principios reflejan algunas de las nociones de desarrollo progresivo abordadas en la primera parte de este artículo, y muestran cómo ideales generales semejantes pueden alimentar las consideraciones de justicia distributiva en Gran Bretaña. Sin embargo, también es importante notar el vínculo explícito entre justicia social y éxito económico, o supervivencia en un mundo competitivo, más cercano a la prevaleciente teoría del desarrollo, que asocia igualdad con crecimiento. Así, "la justicia social no es simplemente un ideal moral, sino una necesidad económica" (IPPR, 1993:19).

Las propuestas prácticas sugieren transformar el estado de bienestar de red de seguridad para periodos problemáticos, en trampolín para la oportunidad económica, incluyendo un mejor acceso a educación y capacitación. Se enfatiza la promoción de opciones, de por vida, en la balanza de empleo, familia, educación, diversión y jubilación. Se propone nutrir a las instituciones sociales, desde la familia hasta el gobierno local, para que proporcionen un ambiente social confiable (IPPR, 1994:20-21). La Comisión pasa su atención, de los cinco grandes males identificados por Beveridge, a lo que se describe como las cinco grandes oportunidades: aprendizaje, trabajo, buena salud, ambiente seguro e independencia financiera a lo largo de toda la vida (IPPR, 1993:50-52).

En esta búsqueda de una nueva dirección para el país, parecían ofrecerse tres futuros distintos. La Comisión rechazó la total libre empresa de la llamada Gran Bretaña de los "desreguladores", por ser un futuro de extremos, donde los ricos se vuelven más ricos y los pobres más pobres. También rechazó lo que se describió como la Gran Bretaña de los "niveladores”, donde se protege a los pobres del continuo deterioro económico con una justicia social lograda vía la redistribución primaria de un sistema de impuestos y beneficios. Lo que decidió apoyar se describe como la Gran Bretaña de los "inversionistas", el escenario de los que favorecen la inversión en un sentido amplio (IPPR, 1994:4):

$$
\begin{aligned}
& \text { Los inversionistas combinan la ética de la comunidad con la } \\
& \text { dinámica de la economía de mercado. Consideran que la } \\
& \text { extensión de la oportunidad económica no es sólo fuente de } \\
& \text { prosperidad económica sino también base de la justicia social. } \\
& \text { Esto exige instituciones sociales, familias y comunidades fuertes, } \\
& \text { que permitan a la gente y a las companíís crecer, adaptarse y } \\
& \text { tener éxito. Invertir en la gente es la principal prioridad. Los } \\
& \text { inversionistas ven en la seguridad, y no en el temor, la base de } \\
& \text { la renovación. Sostienen que si queremos extender la justicia } \\
& \text { social debemos comprometernos con el cambio, ya sea en el } \\
& \text { trabajo o en el hogar, en el gobierno local o en toda Europa. }
\end{aligned}
$$

Debajo del detalle del reporte final de la Comisión (IPPR, 1994) se puede distinguir un núcleo filosófico con tres ideas centrales (White, 1995). La primera es el énfasis en las dotaciones, de modo que la justicia social se logra no por el instrumento convencional de redistribución de ingresos, sino igualando la distribución de dotaciones productivas, como habilidades u oficios (o las capacidades de Sen), que determinan las oportunidades del ciudadano de obtener ingresos y riqueza. La segunda es la noción de que a través de la dispersión de habilidades $u$ oficios la justicia no ahuyenta el rendimiento económico, sino que lo sustenta. $\mathrm{La}$ tercera es un énfasis en la reciprocidad, donde los derechos se equilibran con la responsabilidad de los ciudadanos de aportar algo a la comunidad a cambio de las oportunidades que les fueron ofrecidas. Este contenido moral es raro en el debate de la política británica actual. 

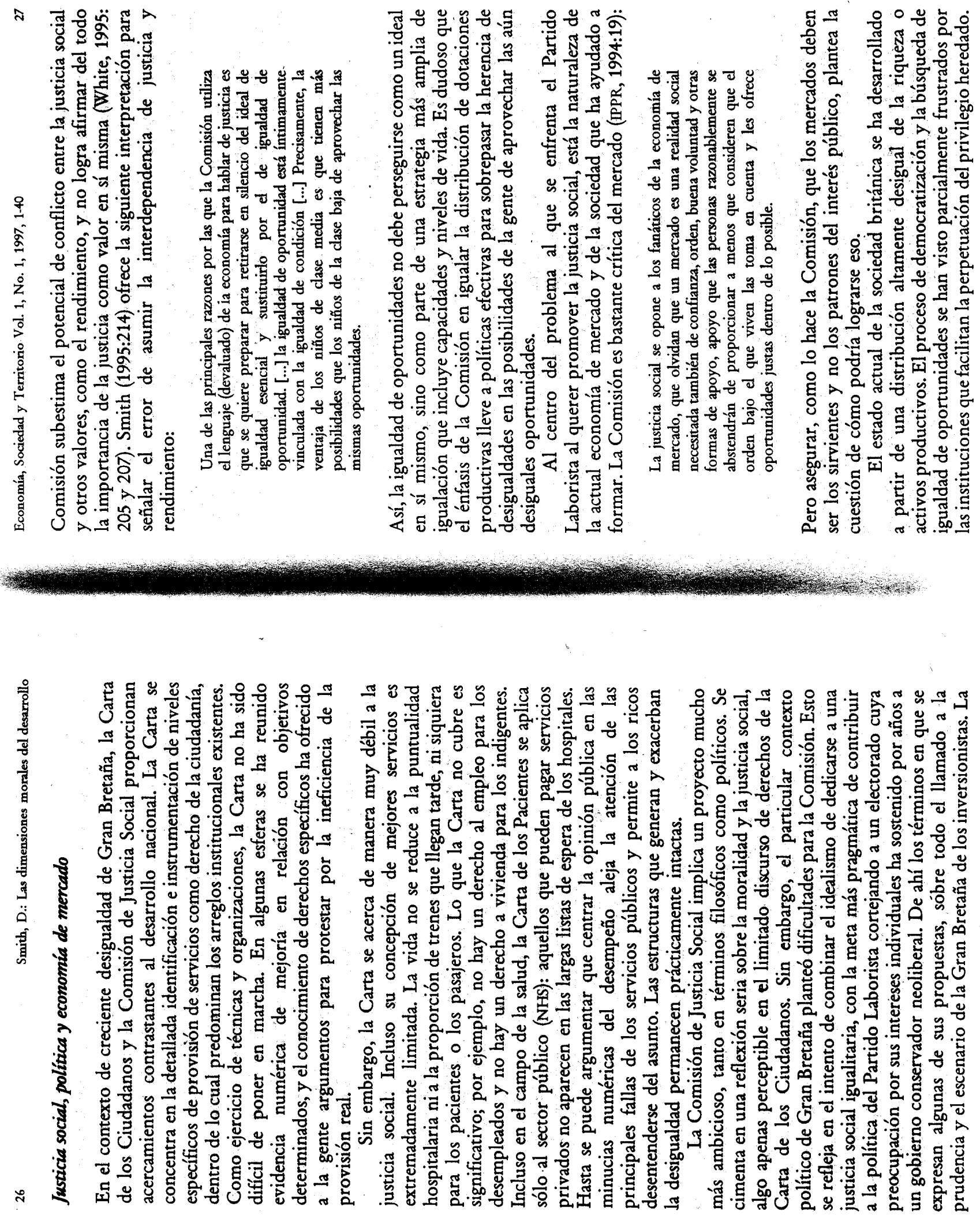
Durante mucho tiempo, a partir de la revolución industrial, la economía elevó los niveles de vida de la clase trabajadora, pero la tendencia actual de los mercados capitalistas es aumentar la desigualdad y la polarización socioeconómica. Si bien estas fuerzas parecen estar fuera del control de las naciones individuales, su efecto se puede mejorar (o empeorar) con las políticas de desarrollo doméstico, y de ahí la importancia de los debates políticos actuales.

Es instructivo considerar la reacción de un expositor del fundamento moral de las instituciones mercantiles y defensor de un estado de bienestar posibilitador, al estudio Rowntree sobre la desigualdad (The Guardian, 17 de febrero, 1995):

El reporte de la fundación Joseph Rowntree [...] es una acusación devastadora a las políticas de libre mercado seguidas durante los últimos 15 años [...] Las políticas neoliberales han acelerado y agravado las poderosas tendencias de desigualdad producidas por los cambios en la economía mundial. [o] allí donde las políicas de desregulación y eliminación del estado de bience bienestar se han aplicado de me desigualdad ha tenido el aumento más espectacular.

Apelando a los sentimientos comunitarios que han comenzado a entrar en el discurso político británico, como se refleja en el reporte de la Comisión de Justicia Social, Gray (1992) se refiere al impresionante poder del mercado desregulado para desgarrar el delicado tejido de relaciones de confianza y civismo que sostiene la cohesión social". Concluye así:

La ráfaga de cambio económico que está arrasando al mundo descalifica cualquier regreso a las viejas formas de democracia social. Nos enfrentamos a la tarea de idear nuevas instituciones y políticas que puedan contener las poderosas tendencias de desigualdad que los libres mercados han dejado sueltas.

Si se quiere diseñar estas estrategias para que hagan más que simplemente contener tendencias actuales, y si se las quiere defender con verdadero convencimiento, se necesitan fundamentos y dirección morales. Esto requiere reconsiderar qué es un buen nivel de vida, yendo bastante más allá del tipo de buena sociedad evocada por la Comisión de Justicia Social (IPPR, 1994, cap. 8), con su insistencia en fortalecer las familias vía la reforma de los beneficios, regeneración de las comunidades, mejoramiento de la vivienda, descentralización estatal y promoción del servicio comunitario voluntario. Se requieren cambios substanciales y, para la mayoría de la gente, inimaginables, en los estilos de vida prevalecientes. No es difícil sostener una causa moral para una forma de vida más cooperativa, sensible y cohesiva, menos dominada por la obtención y el consumo, en la cual el hecho de extender el cuidado de los otros más allá de la familia, la comunidad local o incluso la nación, restringe de manera bastante estricta la desigualdad. Lo difícil es convencer a la clase alta que un estilo de vida tal podría ser mejor tanto para ellos mismos como para los menos afortunados.

\section{El caso de Sudáfrica}

Sudáfrica presenta un ejemplo más convencional de estrategia de desarrollo dirigida a aliviar la extensa y extrema pobreza característica de las partes más pobres del mundo. Pero también tiene sus propios rasgos distintivos, principalmente la discriminación y desigualdad racial heredada por el apartheid. A primera vista el problema moral de base es bastante claro: la raza es un accidente de nacimiento y no una identidad elegida, y no puede producir crédito ni rechazo moral, por lo cual no debería afectar las oportunidades de vida. La evidente prioridad de la Sudáfrica posapartheid es la eliminación de la desigualdad racial, así como la severa pobreza que aqueja a gran parte de la población negra o africana. Sin embargo, las políticas de desarrollo dirigidas a la igualación enfrentan problemas, algunos de los cuales son parecidos a los de Gran Bretaña.

\section{Desigualdad racial}

Con el apartheid la población sudafricana fue clasificada en cuatro grupos raciales: la mayoría africana (como tres cuartas partes de la población total de aproximadamente $\mathbf{4 2}$ millones), los blancos, los mestizos y los asiáticos o indios. Las cifras de las fuentes oficiales (compiladas en el Survey anual del Instituto Sudafricano de Relaciones Raciales y en el South Africa Official Yearbook) revelan marcadas desigualdades en varios indicadores económicos y sociales, con los blancos en las mejores posiciones y los africanos en las peores. Por ejemplo, el ingreso mensual promedio por familia de los blancos es más de cinco veces más alto que el de los africanos, y también más alto que el de los indios y mestizos. La tercera parte de las familias africanas vive en la pobreza, de acuerdo con el criterio 
prevaleciente de mínimo nivel de vida. La diferencia entre nacer blanco o africano son aproximadamente doce años de esperanza de vida. Las disparidades raciales en la vivienda muestran que las casas de los blancos tienen un valor promedio diez veces mayor que el de las casas de los africanos, y de éstas menos de $40 \%$ tiene luz eléctrica y drenaje (datos del Household Survey [censo de vivienda] de 1994).

La brecha entre los niveles de vida de blancos y negros fue subrayada por un agregado nacional del Índice de Desarrollo Humano de la ONU, o HDI (O'Donovan, 1995), que combina indicadores de esperanza de vida, ingreso per cápita en términos de poder de compra y nivel educativo en términos de alfabetismo adulto y escolaridad media. El valor del índice para los países más desarrollados se acerca a uno, mientras que para los menos desarrollados es de cero. Sudáfrica en conjunto llega a 0.677 , puntaje comparable con Paraguay, China o el vecino Botswana, y ocupa la posición 86 entre 173 países. La Sudáfrica blanca llega a 0.901, que la coloca en la posición 19, mientras que la Sudáfrica negra (la población africana) obtiene 0.500 y se coloca en la posición 119 . Los puntjes de la población india y mestiza fueron 0.836 y 0.663 respectivamente.

También el alcance de las disparidades regionales en Sudáfrica se ilustra con el HDI. De las nueve regiones administrativas el puntaje más alto corresponde al Cabo Occidental (0.862) y el más bajo al Transvaal Norte $(0.470)$. La ONU considera que los países con un HDI de 0.8 o mayor tienen un nivel alto de desarrollo humano, mientras que un HDI entre 0.5 y 0.8 corresponde a un nivel medio y uno menor a 0.5 a un nivel bajo. De modo que Sudáfrica cubre todo el espectro de desarrollo humano, de alto a bajo. El HDI de las áreas no urbanas es sólo 57\% del de las zonas urbanas, lo cual enfatiza el problema de la pobreza rural (principalmente africana) y la brecha que debe ser eliminada si ha de prevalecer la igualdad racial y espacial.

\section{El Programa de Reconstrucción y Desarrollo}

El apartheid terminó por fin en 1994, cuando el Congreso Nacional Africano (ANC) fue elegido como partido mayoritario en un gobierno interino de unidad nacional. El principal documento de la estrategia de desarrollo del ANC, el Programa de Reconstrucción y Desarrollo o RDP (ANC, 1994), se convirtió en la política oficial del gobierno con la publicación de un White Paper (RSA, 1994). En su

prólogo, el presidente Nelson Mandela reconoció de la siguiente manera las metas principales: "Al centro del Gobierno de Unidad Nacional está el compromiso de abordar realmente los problemas de la pobreza y la fuerte desigualdad evidente en casi todos los aspectos de la sociedad sudafricana" (RSA, 1994:i).

El RDP se describe como un marco coherente de políticas socioeconómicas. Está guiado por los siguientes principios básicos: un programa integrado y sustentable, un proceso dirigido por el pueblo, paz y seguridad para todos, construcción nacional, vinculación de la reconstrucción, desarrollo y democratización. Éstos reflejan las circunstancias distintivas de la reemergencia sudafricana después del apartheid: control central del gobierno, lucha política violenta, desunidad nacional y ausencia de derechos democráticos para la mayoría de la población.

Se hace un gran énfasis en cubrir las necesidades humanas básicas. "La primer prioridad es comenzar a satisfacer las necesidades básicas de la gente -empleos, tierra, vivienda, agua, electricidad, telecomunicaciones, transporte, un ambiente limpio y sano, nutrición, atención a la salud y bienestar social” (ANC, 1994:7). No se requiere una indagación filosófica profunda para identificar estas necesidades y los sectores de la población a los que se aplican, y Mandela (1994:293) ha reconocido su universalidad: "los pobres de cualquier parte son más parecidos que diferentes”.

La priorización de las necesidades básicas implica gastar más en servicios públicos para los pobres o reubicar los recursos existentes para compensar las desigualdades raciales del pasado. Se espera que esto aumente las posibilidades de que las personas hasta ahora desprovistas, en su mayoría africanos, aprovechen las oportunidades creadas en principio (aunque no necesariamente en la práctica) por la abolición de la discriminación racial. Sólo entonces puede haber esperanza de reducir las diferencias en los niveles de vida, en un proceso de igualación racial.

El documento continúa: "El objetivo central de nuestro RDP es mejorar la calidad de vida de todos los sudafricanos, y en particular la de los sectores más pobres y marginados de nuestras comunidades" (ANC, 1994:15). Esto se podría interpretar como una invocación a la justicia rawlsiana, en términos de beneficios para los más desventajados, pero con la cláusula adicional de que no ha de haber perdedores -consistente con el criterio de Pareto de la economía neoclásica, por el cual el bienestar global aumenta si algunos mejoran, con tal de que nadie empeore. También se hace referencia a lograr la igualdad a través de la redistribución. Todo 


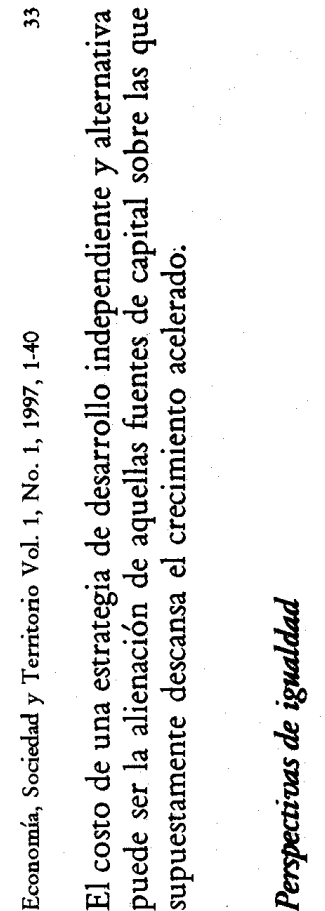

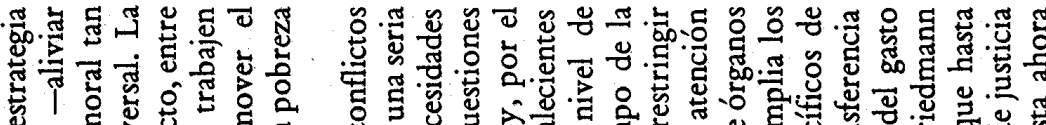

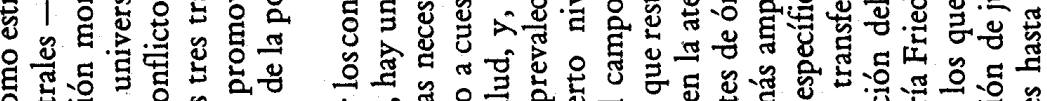

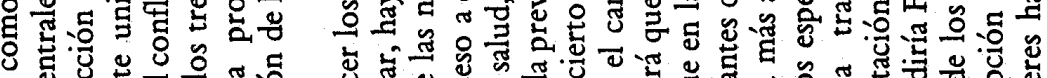

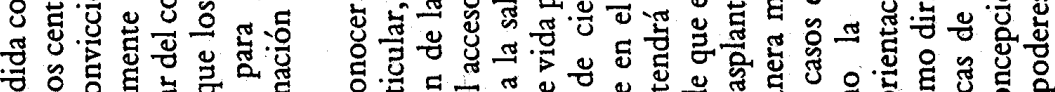

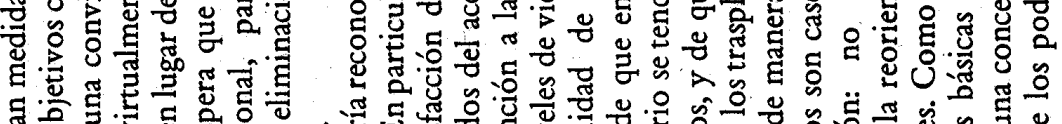

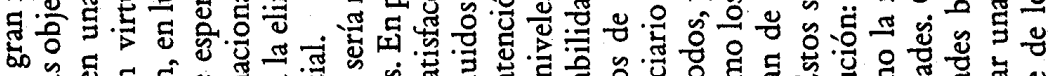
ปै

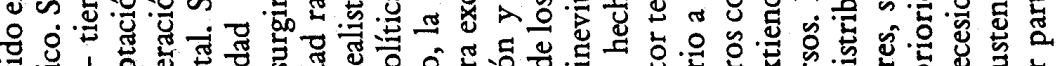

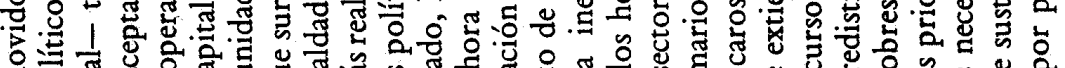

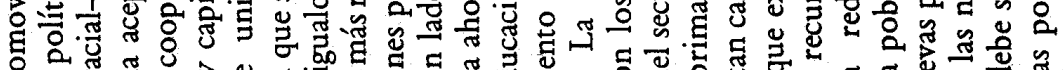

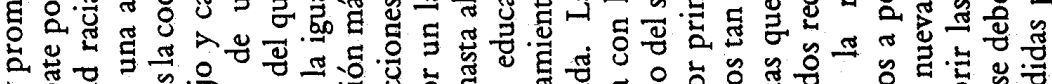

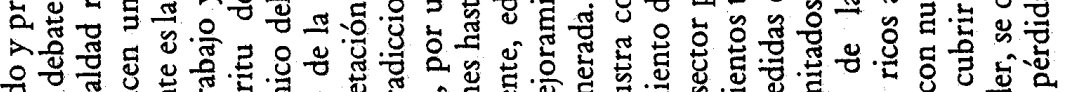

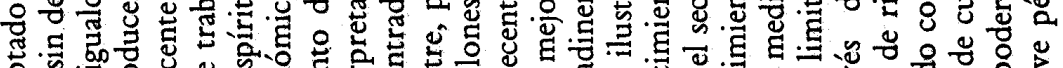

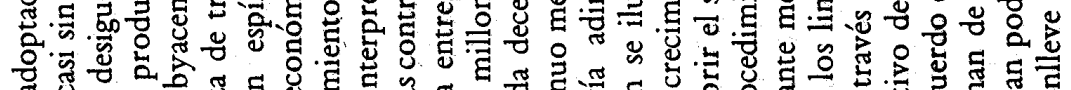

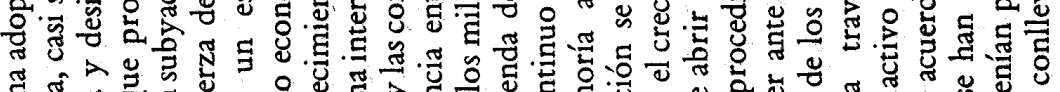

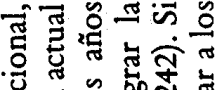

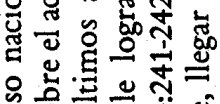

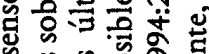

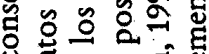

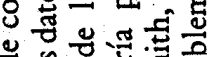
y

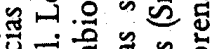

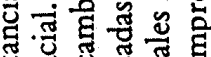

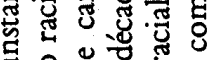

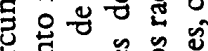

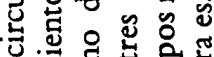

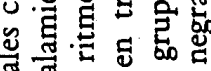

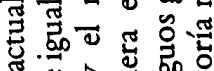
实入.

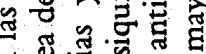

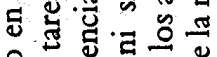

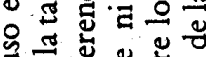

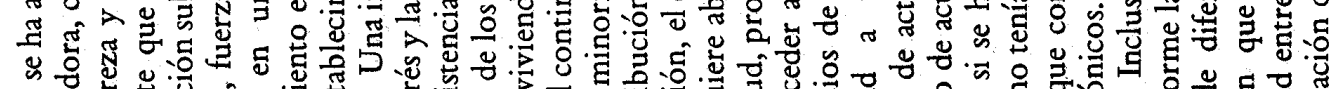

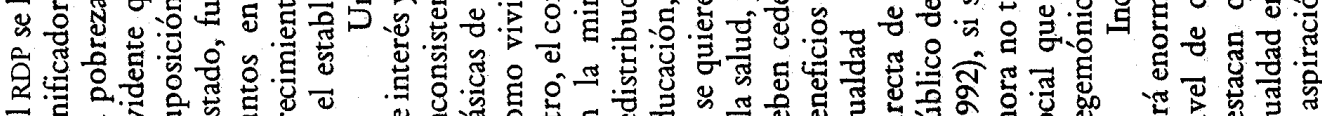

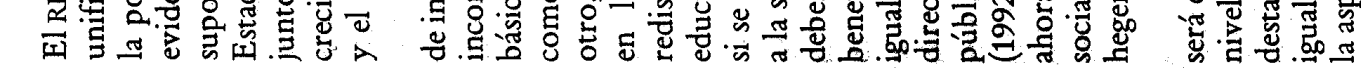
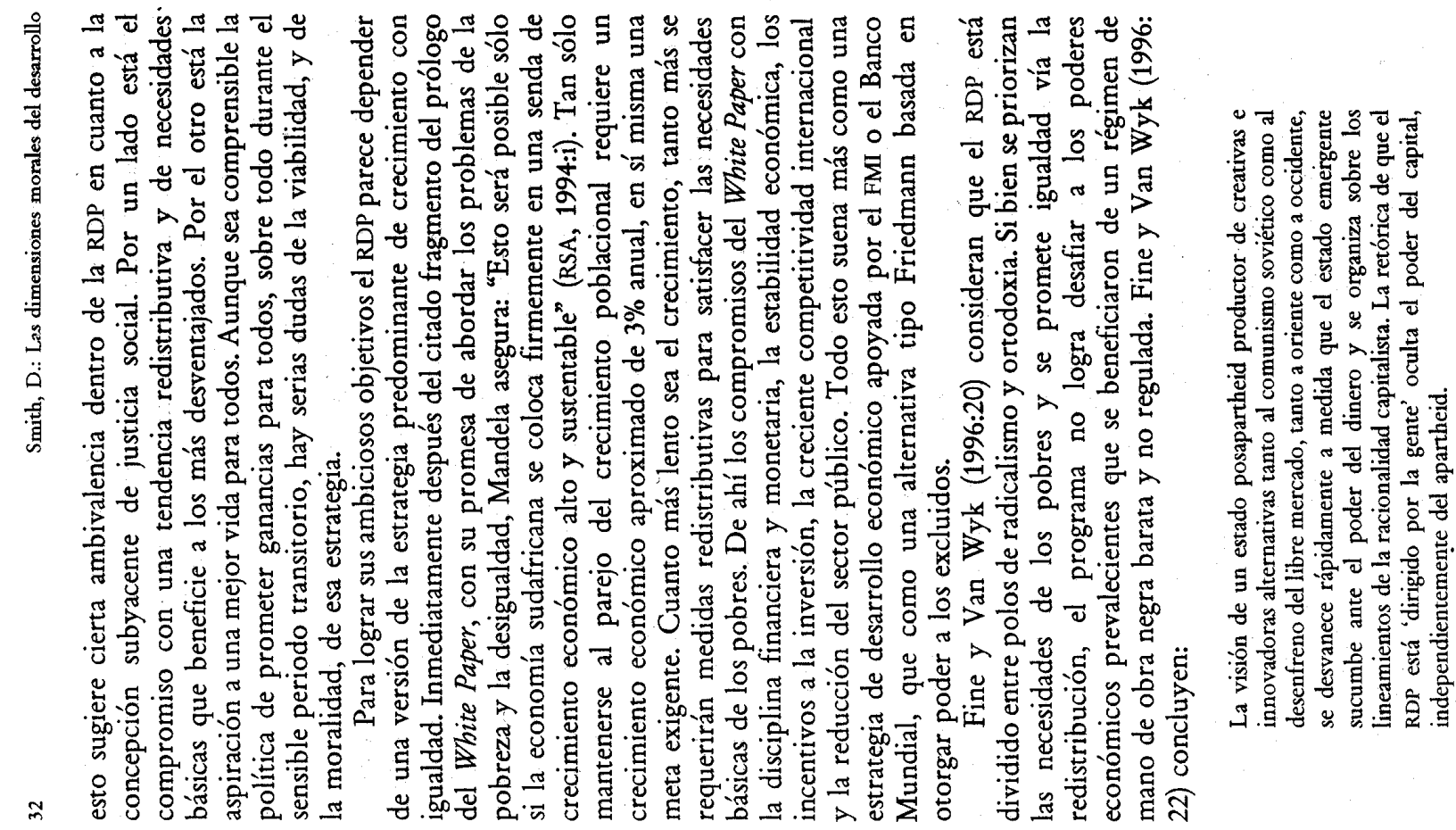


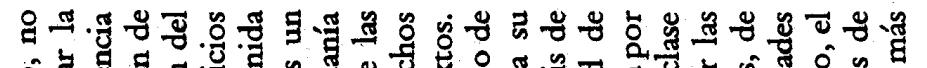

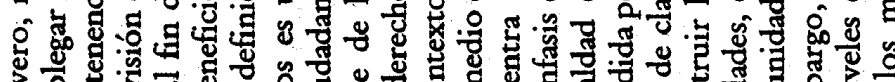

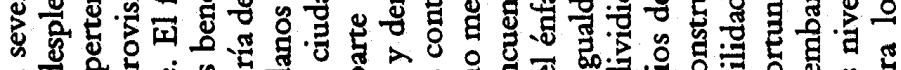

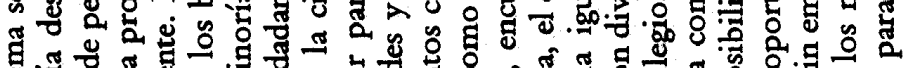

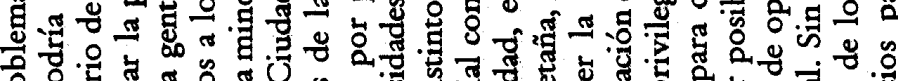

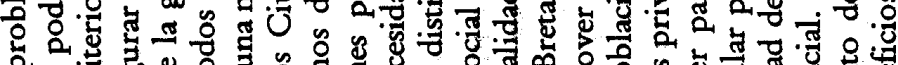

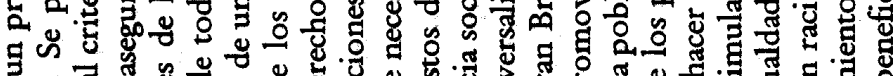

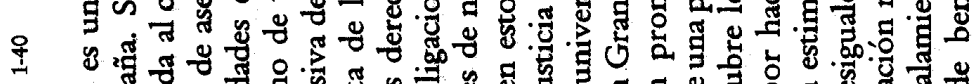
大

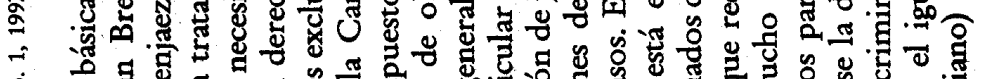

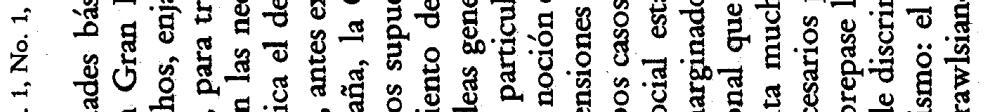

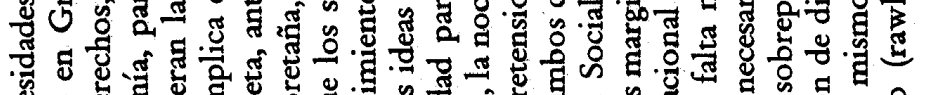

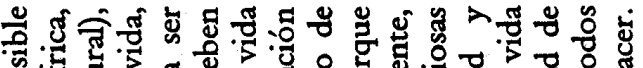

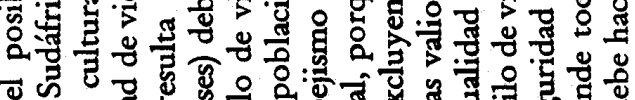
త

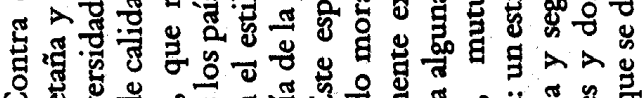

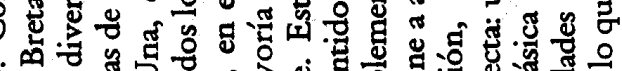
क

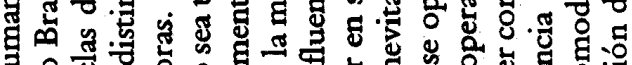

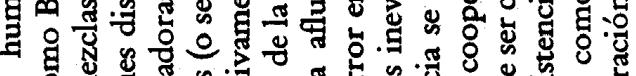

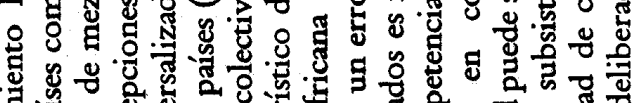

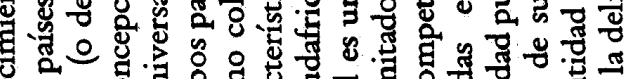

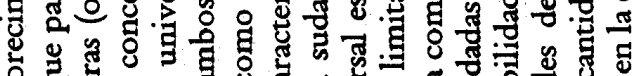

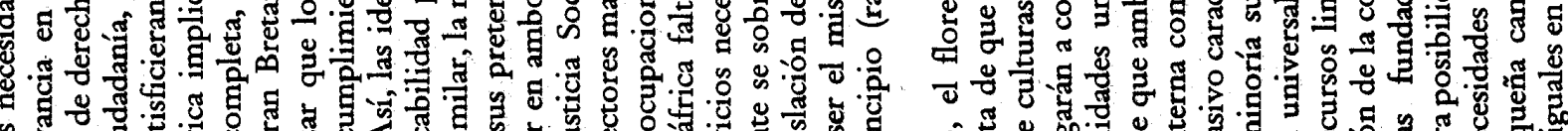

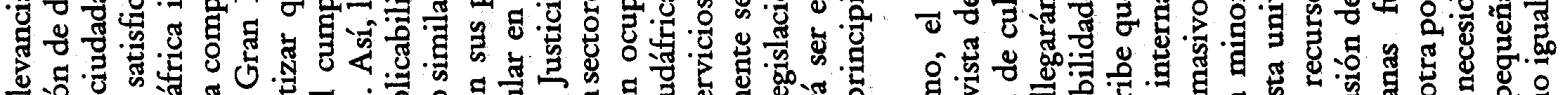

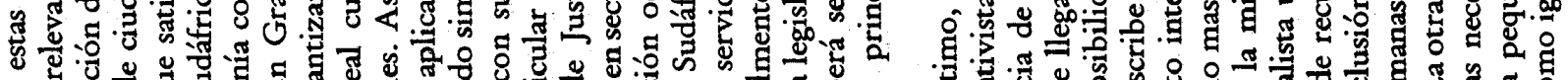
\&

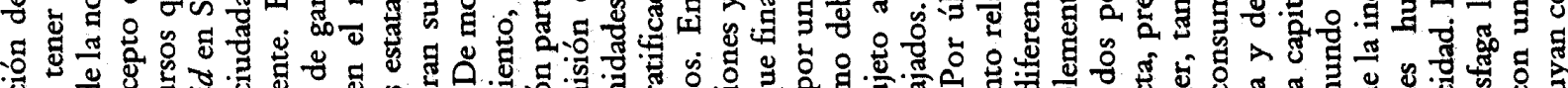

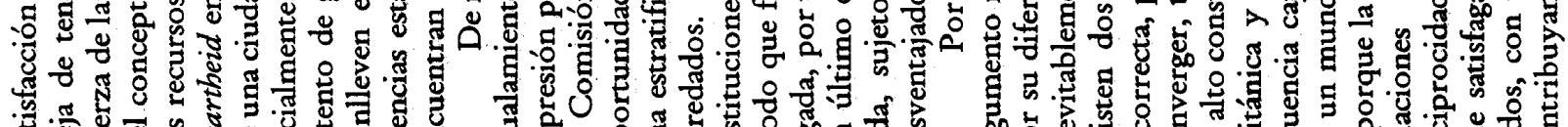

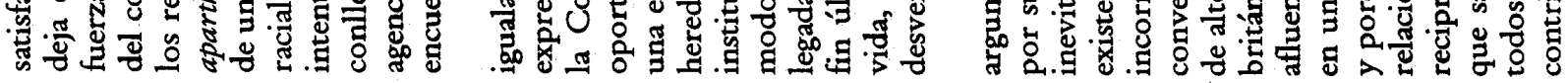
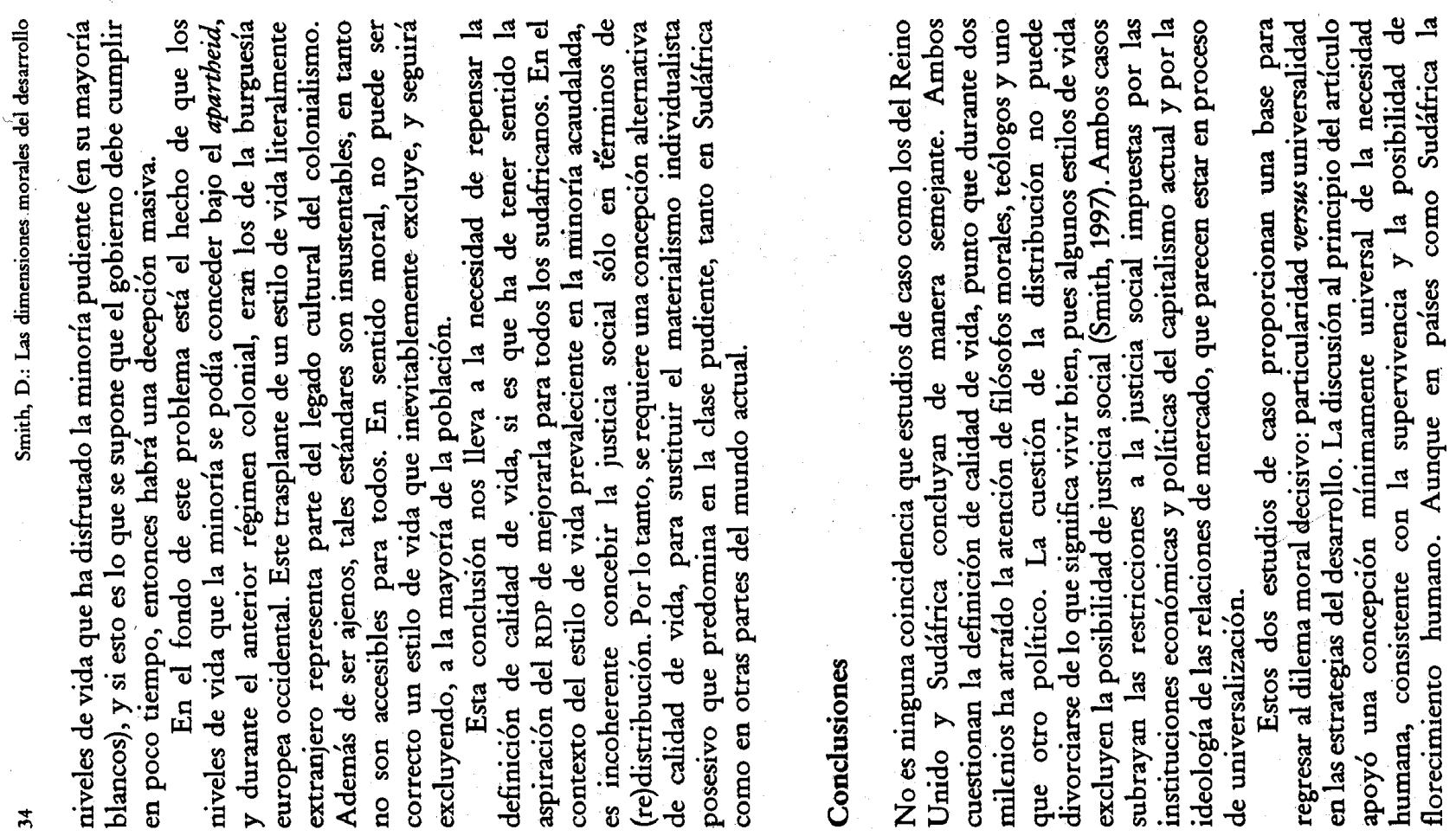
Un estilo de vida así incluiría a todas las personas, con cierta redistribución de recursos, y su modestia dejaría poco lugar para la desigualdad. La cuestión moral de definir un buen nivel de vida no ha perdido su pertinencia, aunque quizás sea más fácil de resolver en la teoría que en la práctica.

\section{Agradecimientos}

El estudio de caso del Reino Unido está basado en un trabajo presentado en el Segundo seminario geográfico Gran BretañaGeorgia, del Queen Mary and Westfield College de Londres, en julio de 1995 (Smith, 1996). El estudio de caso de Sudáfrica se basó en material presentado en la Primer Conferencia Internacional de Geografía de la Universidad de Durban-Westville en Durban en julio de 1995, y en el Tercer Simposio sobre la Geografía de Sudáfrica, Royal Holloway, en Londres, en septiembre de 1995. Se agradece el apoyo financiero de la Academia Británica y del Consejo Británico.

\section{Bibliografía}

ANC (1994), The Reconstruction and Development Programme: $A$ Policy Framework, Johannesburgo, African National Congress.

Attfield, R. y Wilkins, B. (eds.) (1992), International Justice and the Third World, Londres, Routledge.

Bader, V. (1995), Citizenship and exclusion: radical democracy, community, and justice. Or, what is wrong with communitarism?, Political Theory, 23 (2), pp. 211-246.

Beitz, C.R. (1991), Sovereignty and morality in international affairs, en Held, D. (ed.), Political Theory Today, Cambridge, Polity Press, pp. 236-254.

Benhabib, S. (1992), Situating the Self: Gender, Community and . Postmodernism in Contemporary Ethics, Cambridge, Polity Press.
Black, R. (1996), Immigration and social justice, Transactions of the Institute of British Geographers, 21 (1), pp. 6475.

Brown, A. (1986), Modern Political Philosophy: Theories of the Just Society, Harmondsworth, Penguin.

Campbell, T. (1988), Justice, Basingstoke, Macmillan.

Corbridge, S. (1993), Marxism, modernities, and moralities: development praxis and the claims of distant strangers, Environment and Planning D: Society and Space, 11, pp. 449472.

Doyal, L. y Gough, I. (1991), A Theory of Human Need, Londres, Macmillan.

Fine, R. y Van Wyk, G. (1996), South Africa: state, labour, and the politics of reconstruction, Capital and Class, 58, pp. 19-31.

Freidman, M. (1991), The practice of partiality, Etbics, 101, pp. 813835 .

Friedmann, J. (1992), Empowerment: The Politics of Alternative Development, Oxford, Blackwell.

Gewirth, A. (1994), Is cultural pluralism relevant to moral knowledge?, en Paul, E.F., Miller, F.J. y Paul, J. (eds.), Cultural Pluralism and Moral Knowledge, Cambridge, Cambridge University Press, pp. 22-43.

Gray, J. (1992), The Moral Foundations of Market Institutions, Londres, Institute of Economic Affairs.

Griffin, J. (1986), Well-being: Its Meaning, Measurement and Moral Importance, Oxford, Clarendon Press.

Hekman, S.J. (1995), Moral Voices, Moral Selves: Carol Gilligan and Feminist Moral Theory, Cambridge, Polity Press.

Hudson, R. y Williams, A. (1994), Divided Britain, 2da. edición, Chichester, Bellhaven. 
Hutton, W. (1995), The State We're In, Londres, Jonathan Cape.

IPPR (1993), The Justice Gap, Commission on Social Justice, Discussion Paper 1, Londres, Institute for Public Policy Research.

(1994), Social Justice: Strategies for National Renewal, Report of the Commission on Social Justice, Londres, Vintage.

Kekes, J. (1994), Pluralism and the value of life, en Paul, E.F., Miller, F.J. y Paul, J. (eds.), Cultural Pturalism and Moral Knowledge, Cambridge, Cambridge University Press, pp. 44 60.

Kymlicka, W. (1990), Contemporary Political Philosopby: An Introduction, Oxford, Clarendon Press.

Mandela, N. (1994), Long Walk to Freedom, Londres, Little, Brown \& Co.

Miller, R. W. (1992), Moral Differences: Truth, Justice and Conscience in a World of Conflict, Princeton, Princeton University Press.

Nozick, R. (1974), Anarchy, State, and Utopia, Nueva York, Basic Books [Anarquía, estado y utopía, México, FCE, 1988].

O'Donovan, M. (1995), Indicating Development: the Human Development Index, Indicator South Africa, 12 (3), pp. 91-95.

O’Neill, O. (1991), Transnational justice, en Held, D. (ed.), Political Theory Today, Cambridge, Polity Press, pp. 276-304.

Peffer, R.G. (1990), Marxism, Morality, and Social Justice, Princeton, Princeton University Press.

Rawls, J. (1971), A Theory of Justice, Cambridge, Mass, Harvard University Press [Teoría de la justicia, México, FCE, 1978].
Rorty, R. (1989), Contingency, Irony, and Solidarity, Cambridge, Cambridge University Press [Contingencia, ironía y solidaridad, Barcelona, Paidós, 1991].

Rowntree (1995), Income and Wealth, Report of the Inquiry Group into Income and Wealth, York, Joseph Rowntree Foundation.

RSA (1994), White Paper on Reconstruction and Development: Government Strategy for Fundamental Transformation, Republic of South Africa, Pretoria.

Sandel, M.J. (1982), Liberalism and the Limits of Justice, Cambridge, Cambridge University Press.

Sen, A. (1992), Inequality Reexamined, Oxford, Clarendon Press.

Smith, D.J. (1995), Review of Social Justice: Strategies for National Renewal; The Report of the Commission on Social Justice, The Political Quarterly, 66 (3), pp. 211-214.

Smith, D.M. (1994), Geograpby and Social Justice, Oxford, Blackwell.

(1996), Inequality and social justice in contemporary Britain, en Gachechiladze, R. y Smith, D.M. (eds.), Economic, Social and Political Aspects of Urban and Regional Change, Tbilisi, Tbilisi State University Press (en prensa).

(1997), Back to the good life: towards an enlarged conception of social justice, Environment and Planning $D$ : Society and Space (en prensa).

The Citizen's Charter (1994), Report Back 1994, Londres, HMSO.

The Patient's Charter (1994), Hospital and Ambulance Services: Comparative Performance Guide 1993-1994, Londres, Department of Health.

(1995), The Patient's Charter \& You, Londres, Department of Health. 